\title{
The p21-activated kinases in neural cytoskeletal remodeling and related neurological disorders
}

\author{
Kaifan Zhang ${ }^{1,2}$, Yan Wang ${ }^{1 \bowtie}{ }_{(\mathbb{D}}$, Tianda Fan ${ }^{2}$, Cheng Zeng ${ }^{1,3}$, Zhong Sheng Sun ${ }^{1,2,3,4 \bowtie}$ \\ ${ }^{1}$ Beijing Institutes of Life Science, Chinese Academy of Sciences, Beijing 100101, China \\ 2 Institute of Genomic Medicine, Wenzhou Medical University, Wenzhou 325000, China \\ ${ }^{3}$ CAS Center for Excellence in Biotic Interactions, University of Chinese Academy of Sciences, Beijing 100049, China \\ ${ }^{4}$ State Key Laboratory of Integrated Management of Pest Insects and Rodents, Chinese Academy of Sciences, Beijing \\ 100101, China \\ $\square$ Correspondence: wangy@biols.ac.cn (Y. Wang), sunzs@biols.ac.cn (Z. S. Sun)
}

Received July 2, 2020 Accepted November 19, 2020

\begin{abstract}
The serine/threonine p21-activated kinases (PAKs), as main effectors of the Rho GTPases Cdc42 and Rac, represent a group of important molecular switches linking the complex cytoskeletal networks to broad neural activity. PAKs show wide expression in the brain, but they differ in specific cell types, brain regions, and developmental stages. PAKs play an essential and differential role in controlling neural cytoskeletal remodeling and are related to the development and fate of neurons as well as the structural and functional plasticity of dendritic spines. PAK-mediated actin signaling and interacting functional networks represent a common pathway frequently affected in multiple neurodevelopmental and neurodegenerative disorders. Considering specific small-molecule agonists and inhibitors for PAKs have been developed in cancer treatment, comprehensive knowledge about the role of PAKs in neural cytoskeletal remodeling will promote our understanding of the complex mechanisms underlying neurological diseases, which may also represent potential therapeutic targets of these diseases.
\end{abstract}

KEYWORDS p21-activated kinases, expression pattern, synaptic cytoskeletal remodeling, neuronal function, neurological diseases

Kaifan Zhang and Yan Wang contributed equally to this work.

\section{INTRODUCTION}

Most neurons receive information from other neurons via synapses mainly formed on the surface of dendritic spines. Thus, the morphological plasticity and density of dendritic spines are crucial for the physiological functions of neurons. Dendritic spines consist of a network of actin filaments, whose polymerization and depolymerization can govern spine function and regulate synaptic plasticity. Dysfunction of synaptic cytoskeletal remodeling is closely related to diverse brain disorders (Yan et al., 2016). As the initially identified and main downstream effectors of the Rho family small GTPases Cdc42 and Rac1, PAKs (p21-activated kinases) represent a family of serine/threonine kinases that can connect cytoskeletal dynamics, mechanical forces, and neuron morphology (Daniels and Bokoch, 1999; Nobes and Hall, 1999). It is widely recognized that PAKs play a potent and diversified role in controlling the morphology, motility, and fate of neurons to maintain the normal function of dendritic spines (Manser et al., 1994; Jaffer and Chernoff, 2002; Rane and Minden, 2014).

To date, six PAKs have been identified in mammals. Based on their structural differences and sequence homologies, PAKs are classified into two groups. PAK1, PAK2, and PAK3 belong to group I, whereas PAK4, PAK5, and PAK6 belong to group II (Fig. 1) (Sells and Chernoff, 1997; Knaus and Bokoch, 1998; Daniels and Bokoch, 1999). Overall, group I PAKs have higher sequence similarity than group II PAKs in the PBD (p21-binding domain) and kinase domains, but differ throughout their other domains (Eswaran et al., 2008). Specifically, group I PAKs contain one PBD that 





PBD domain



Kinase domain



PBD domain

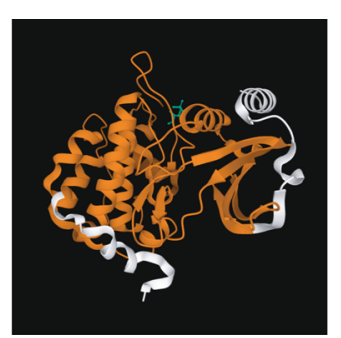

Kinase domain

Figure 1. Domains and structural features of PAKs. (A) Schematic representation of domains of PAKs; PAKs are classified into two group, group I PAKs and group II PAKs. All members of PAKs contain a conserved N-terminal p21-binding domain (PBD) and a C-terminal kinase domain (KD). (B) Protein structure of PBD and KD in PAK1. PBD binds Cdc42/Rac1. (C) Protein structure of PBD and KD in PAK4.

overlaps an AID (autoinhibitory domain) in the $\mathrm{N}$-terminus, and one serine/threonine kinase domain in the C-terminus (Knaus and Bokoch, 1998). The PBD serves as the binding site of active Cdc42 and Rac GTPases (Jaffer and Chernoff, 2002). The AID binds to the kinase domain of another PAK to form an inactive homodimer (Rane and Minden, 2014). The homodimer is dissociated once Rho GTPases bind to the PBD domain, which then leads to conformational reorganization and subsequent autophosphorylation at multiple sites (Rane and Minden, 2014). The autophosphorylation in the kinase domain allows the binding of group I PAKs to the substrate and exerting of its catalytic function in a monomeric conformation (Jaffer and Chernoff, 2002). There are other domains in the N-terminal of group I PAKs, including conserved SH3 (Src homology 3)-binding motifs for binding to adaptor proteins, such as NCK1 (NCK adaptor protein 1) and GRB2 (growth factor receptor-bound protein 2), and the PIX binding domain for PAK-interacting exchange factor/ Cool (PIX/Cool), such as nucleotide-exchange factor PIX (Lei et al., 2000; Parrini et al., 2002; Pirruccello et al., 2006). In contrast, group II PAKs contain a PBD and an AID (for PAK5) or a PSD (pseudosubstrate domain) (for PAK4 and $\mathrm{PAK6}$ ) in the $\mathrm{N}$-terminus, and a serine/threonine kinase domain in the C-terminus (Ha et al., 2012; Tabanifar et al., 2016). Group II PAKs are monomers in the inactive state, and the PSD or AID mediates this inactive state by preventing their substrates from entering the catalytic site (Gao et al., 2013; Wang et al., 2013). Group II PAKs show greater binding affinity to Cdc42 than to Rac1 (Arias-Romero and Chernoff, 2008). Although the PBD is present in group II PAKs, whether its role is similar to that in group I PAKs remains debatable. Normally, the contact between Cdc42 and the PBD of group II PAKs alters their intracellular location (Chenette et al., 2006). In addition to the PBD, additional interactions of Cdc42-PAK may suppress the kinase activity and contribute to the regulation of its inactive state (Fig. 1). For example, Cdc42 binds to the PBR (polybasic region) and C-terminal lobe of PAK4 and inhibits the kinase activity in vitro ( $\mathrm{Ha}$ and Boggon, 2018).

PAKs serve as key regulators of cell growth, cytoskeletal dynamics, cell morphology, cell migration, and cell cycle progression, as well as of death and survival events. Previous studies have indicated that dysfunction of PAKs can result in cancer development and progression, and small molecules that regulate PAK activity have been used for the treatment of multiple cancers (Radu et al., 2014). Recently, 
emerging evidence indicates that PAKs are essential for spine morphogenesis, neural plasticity, and brain-related functions and behaviors. In particular, the actin signaling networks mediated by PAKs represent a common pathway frequently affected in multiple neurodevelopmental and neurodegenerative disorders, including autism, mental retardation, and schizophrenia (Allen et al., 1998; Zhao et al., 2006; Huang et al., 2011; Dolan et al., 2013; HayashiTakagi et al., 2014; Harms et al., 2018; Wang et al., 2018; Horn et al., 2019). In this review, we summarize the recent findings about the functions of PAKs in the nervous system, including the structures and expression patterns of PAKs during brain development. We then discuss the specific functions of PAKs in neural development, migration, polarity, differentiation, and cell fate determination, as well as synaptic and neural cytoskeleton-related synaptic plasticity. Neurological disorders associated with PAK dysfunction are also discussed by integrating multiple levels of evidence from mouse models and human genetics. A comprehensive review of the function of PAKs in synaptic cytoskeleton-related neural function will promote our understanding of the complex molecular mechanisms underlying neurological diseases and help us determine the series of events that lead to the progression of these diseases.

\section{EXPRESSION OF PAKS IN THE NERVOUS SYSTEM DURING BRAIN DEVELOPMENT}

Considering little is known about the expression of PAKs at different developmental stages in the nervous system, we characterized the expression patterns of PAK genes in the human brain by analyzing data from the HBT (Human Brain Transcriptome) database (Johnson et al., 2009; Kang et al., 2011; Pletikos et al., 2014) from the fetal period to after birth. We downloaded transcriptome expression data with the probe IDs corresponding to the PAK gene profiling by array on the Affymetrix Human Exon 1.0 ST Array [transcript (gene) version] Platform in the HBT database from 6 brain regions of 59 donors. The expression value of each PAK gene was averaged using data from both the left and right brain hemispheres of same-age donors. We found that most PAK levels showed a decrease at the late prenatal stage, but each $P A K$ presented a differential pattern in different brain regions, including the DFC (dorsolateral prefrontal cortex), hippocampus, amygdala, mediodorsal nucleus of the thalamus, cerebellar cortex, and striatum, from 40 weeks before birth to 40 years after birth (Fig. 2A). Specifically, PAK1 was highly expressed at every stage of life, especially after birth until adulthood, and it showed a slightly decreasing trend in the striatum, but a generally increasing trend in other regions of the brain during development. In contrast, PAK2 showed high expression levels during the fetal period that were gradually decreased and maintained at a stable low level after birth. PAK3 showed low expression in the striatum and high expression in other brain regions during the fetal period but an obvious decrease in the cerebellar cortex during development. In general, PAK4 expression was relatively stable during the fetal period and after birth. The expression trend of $P A K 5$ was similar to that of $P A K 2$, with the exception that its decline range was slightly lower than that of $P A K 2$. In contrast to $P A K 3, P A K 6$ showed relatively high expression in the striatum and low expression in other brain regions at every stage of life (Fig. 2A). We also analyzed the expression patterns of Pak genes in the adult mouse brain by analyzing the data from in situ hybridization dataset in the Mouse Brain module from the Allen Brain Atlas database (Lein et al., 2007) and found that the expression pattern of Paks at the adult stage in the mouse brain was generally similar to the pattern in the human brain. For example, Pak1 was highly expressed in all detected brain regions; however, the Pak2 level was relatively low in the adult mouse brain (Fig. 2B).

To analyze the cell-type-specific expressions of PAKs in the human brain, we downloaded RNA-Seq data of 99 human postmortem brains and seven cell-type samples from the BRAINcode database (Dong et al., 2018). We found that PAKs were highly expressed in the clusters of SNDA (substantia nigra dopamine neurons) and TCPY (temporal cortex pyramidal neurons), but relatively low expression was found in the clusters of PBMC (peripheral blood mononuclear cells), MCPY (motor cortex pyramidal neurons), and FB (fibroblast) (Fig. 3A). To analyze the cell-type-specific expressions of Paks in the mouse brain, the single cell RNA-seq data from Mousebrain.org, including 133 mouse samples from 19 regions in the central nervous system and peripheral nervous system, were analyzed by droplet microfluidics (10x Genomics Chromium) (Zeisel et al., 2018). We first calculated Paks expression in seven cell types, including astrocytes, ependymal cells, immune cells, neurons, oligodendrocytes, peripheral glial cells, and vascular cells (Fig. 3B and 3C). While Pak1 and Pak3 were highly enriched in the cluster of neurons, Pak2 expression showed relatively higher levels in ependymal cells, neurons, and vascular cells than in other cell types. Notably, Pak1, Pak4 and Pak5 also exhibited relatively high expression in oligodendrocytes (Fig. 3B and $3 \mathrm{C}$ ), suggesting their functions in non-neuronal cells. To provide more specific cell-type information, Pak expression in 20 cell types was also analyzed and calculated using the same data (Fig. 3D and 3E). We found that Paks were expressed in various neuronal and non-neuronal cells, including cholinergic and monoaminergic neurons, hindbrain excitatory neurons, oligodendrocytes and telencephalon excitatory neurons. Specifically, Pak1 was relatively enriched in hindbrain excitatory neurons, Pak2 in the clusters of cholinergic and monoaminergic neurons and enteric neurons, Pak3 in cholinergic and monoaminergic neurons, Pak4 in oligodendrocyte clusters, Pak5 in the clusters of oligodendrocytes and telencephalon excitatory neurons, and Pak6 in the clusters of hindbrain excitatory neurons and telencephalon excitatory neurons. These findings suggest that different PAKs may exert different functions in the brain. 
A
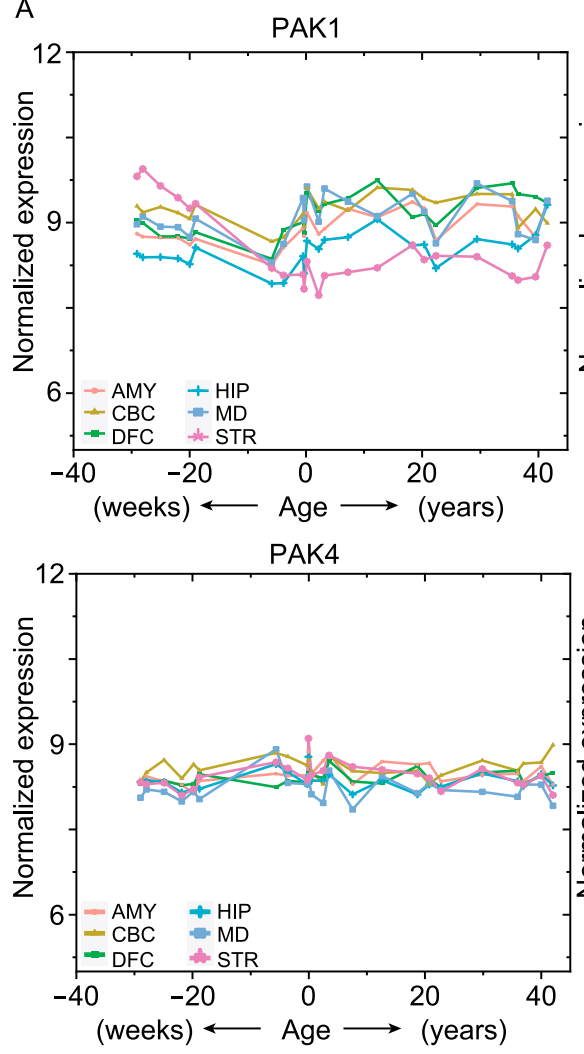



B


Figure 2. PAKs show a differential expressional pattern from the fetal period to after birth in the human and mouse brain. We downloaded transcriptome expression data profiling in the HBT database, with the transcriptome data read by R package "oligo". (A) Scatter plot representation of PAKs expression using transcriptome data. DFC, dorsolateral prefrontal cortex; HIP, hippocampus; AMY, amygdaloid complex; MD, mediodorsal nucleus of thalamus; CBC, cerebellar cortex; STR, striatum. (B) Heatmap presents the expression of each Pak in adult mouse brain in the sagittal plane. OLF, olfactory areas; HPF, hippocampal formation; CTXsp, cortical subplate; STR, striatum; PAL, pallidum; TH, thalamus; HY, hypothalamus; MB, midbrain; P, pons; MY, medulla; CB, cerebellum.

\section{FUNCTION OF PAKS IN NEURAL CYTOSKELETAL REMODELING}

The F-actin (filamentous actin) cytoskeleton is the main driving force behind dendritic spine remodeling and maintenance of synaptic plasticity. Cofilin is a major actin-depolymerizing factor that regulates the actin cytoskeleton dynamics and phosphorylation of serine residue at 3 (Ser 3) can inhibit its actin-depolymerizating activity (Yang et al.,
1998). PAK can phosphorylate cofilin at Ser3 via LIMK1/2 (LIM motif-containing protein kinases 1 and 2) to prevent F-actin depolymerization (Arber et al., 1998; Yang et al., 1998; Li et al., 2013; Wang et al., 2018). Due to their high expression in the adult brain, the group I PAKs, particularly PAK1 and PAK3, are the most extensively studied mammalian PAKs for their function in brain and behavior. However, emerging studies indicate that other PAKs also play important roles in the formation and maintenance of dendritic 
spines and activity-dependent synaptic plasticity via regulating actin cytoskeleton dynamics (Manser et al., 1994; Rane and Minden, 2014). To date, PAKs have been found to be involved in diverse neural developmental processes, such as PAK1/2/3/6 in neuronal migration (Causeret et al., 2009; Pensold et al., 2017; Wang et al., 2018; Liu et al., 2019), PAK1/3/6 in neurite outgrowth (Cobos et al., 2007; Li et al., 2013; Civiero et al., 2015), PAK1 in neuronal polarity (de la Torre-Ubieta et al., 2010), PAK1/3 in neuronal differentiation (Li et al., 2013; Maglorius Renkilaraj et al., 2017), and PAK1/4 in axonal development (Hing et al., 1999; Qu et al., 2003; Chen et al., 2009). In the following sections, we summarize how PAKs are involved in maintaining the structural and functional plasticity of dendritic spines by regulating actin cytoskeletal networks. A detailed summary of the function of each PAK in neural development and processes is summarized in Table 1. Established mouse models for each member of the PAK family are also summarized in Table 2.

\section{Synaptic plasticity}

Synaptic plasticity is closely related to the morphology and density of dendritic spines, wherein F-actin is highly expressed and forms a complex cytoskeletal network. PAKs can control the polymerization and depolymerization of F-actin and play an indispensable role in synaptic plasticity (Kreis and Barnier, 2009). Abnormal activation of Rac-PAK or Rac-GEF/PAK signaling can result in aberrant actin polymerization, increased spine density, and the suppression of spine maturation (Nobes and Hall, 1995; Nobes and Hall, 1999; Byrne et al., 2016). Mice overexpressing an autoinhibitory-negative PAK in the postnatal forebrain showed fewer spines, and synapse distribution in these mice exhibited a shift toward synapses of larger size, suggesting the direct contribution of PAK catalytic activity to synaptic plasticity (Hayashi et al., 2004). The Rac/PAK signaling pathway is also required for the rapid stabilization of newly formed polymers of actin filaments induced by stimulation, and thus for activity-induced changes of spine morphology and synaptic plasticity (Chen et al., 2010). In addition to its regulation of actin dynamics at postsynaptic spines, PAK activation also regulate presynaptic actin network and is required for the formation of actin-based filopodia in presynaptic terminals related to long-term memory (Udo et al., 2005).

PAKs dysfunction has induced abnormal synaptic morphology and functional impairments in synaptic plasticity and behavior in mice. For example, Pak1 knockout mice showed deficits in spine actin filaments and NMDA-induced cofilin activity as well as dramatically reduced hippocampal LTP (long-term potentiation) (Asrar et al., 2009). Mice lacking the gene Pak3 exhibited reduction in phosphorylated CREB levels but normal actin cytoskeleton, possibly due to the compensatory roles of other PAK family members in the brain (Meng et al., 2005). Consequently, a selective deficit in hippocampal late-phase LTP as well as deficiencies in hippocampus-independent learning tasks were found in the Pak3 knockout mice (Meng et al., 2005). PAK3 can be specifically recruited to the head of the activated spine by activity to control activity-mediated local spine growth and synaptic connectivity. Inhibition of PAK3 in a rat hippocampal slice induced the growth of new, unstable spines and an impairment of activity-dependent spine stabilization (Dubos et al., 2012). Notably, Pak1/Pak3 double-knockout mice showed a robust microcephaly phenotype in postnatal brain growth (Huang et al., 2011). Increased neural and glial cell density but reduced dendritic arbors and axons and enlarged individual synapses in the CA1 region of the hippocampus, along with enhanced basal synaptic transmission and reduced LTP and LTD (long-term depression), were also evident in the double-knockout mice (Huang et al., 2011). Moreover, our recent study indicated that PAK2 dysfunction resulted in decreased synapse densities, attenuated LTP, and autism-related behaviors in mice (Wang et al., 2018).

In addition to neuronal morphology, PAKs regulate synaptic transmission and trafficking. For example, PAK3 controls the surface trafficking of the major excitatory receptor GluA1 AMPAR (AMPA receptor) subunit in neurons (Hussain et al., 2015). PAKs can interfere with Shank3 to regulate NMDAR membrane delivery or stability (Duffney et al., 2013). PAKs can also control synaptic GABA(A)R surface stability via GIT1 (G protein-coupled receptor kinase interacting ArfGAP 1)/ $\beta$ PIX signaling (Smith et al., 2014). PAK signals function as the downstream of the scaffolding protein SAP102 and EphB2 to regulate synaptic AMPAR trafficking and localization in the neonatal cortex of mice (Murata and Constantine-Paton, 2013). Moreover, PAKs can function downstream of AMPK (AMP-activated protein kinase) and regulate the activity of excitatory synapses in AgRP (agouti-related peptide) neurons to produce fastinginduced plasticity (Banko et al., 2011; Kong et al., 2016). When AgRP neurons are activated, AMPK can phosphorylate PAK2 and its target LIMK2. Inhibition of PAK by overexpressing AID in the arcuate nucleus greatly decreased AgRP neuron activity, mEPSCs (miniature excitatory postsynaptic currents) frequency and body weight of fasted mice, suggesting that PAKs is required for fasting- and AMPKinduced effects on excitatory synaptic plasticity (Kong et al., 2016). PAK1 can maintain the balance of excitation and inhibition through endocannabinoid signaling (Xia et al., 2016). PAK1 up-regulates synaptosomal COX-2 (cyclooxygenase-2) expression, which then decrease endocannabinoid signaling and facilitate inhibitory synaptic transmission by increasing GABA transmission. PAK1 disruption in mice resulted in suppressed inhibitory neurotransmission through reducing COX-2 expression and increasing endocannabinoid secretion (Xia et al., 2016). PAK-cofilin-mediated actin PAK signaling regulates synaptic function in the entorhinal cortical to dentate gyrus circuit (EC-DG) and play a critical role in social recognition memory retrieval (Leung et al., 2018). Inducible disruption of PAK signaling impairs synaptic 
transmission at the EC-DG terminals and selectively impairs social recognition memory (Leung et al., 2018). Moreover, PAK5 can phosphorylate Pacsin1 and Synaptojanin1, two proteins that regulate synaptic vesicle endocytosis and recycling, suggesting the role of PAK5 in synaptic vesicle trafficking (Strochlic et al., 2012).

PAKs can regulate synaptic plasticity by affecting important signaling pathways. For example, the scaffolding proteins MAGUKs (membrane-associated guanylate kinases), such as SAP102, can interact with EphB2 and Kalirin-7, a neuronal exchange factor for small GTPase, to activate their key downstream PAK signals (Murata and Constantine-Paton, 2013). The EphB/SAP102/PAK signaling can regulate synaptic AMPAR trafficking and localization in the neonatal cortex of mice and thus has critical roles in cortical synapse development (Murata and Constantine-Paton, 2013). The FMRP-CYFIP1-eIF4E inhibitory complex can maintain the appropriate polymerization and stabilization of actin filaments in response to synaptic activity by inhibiting Rac1PAK1/2 activation, which is fundamental for generating multiple forms of long-term synaptic plasticity at glutamatergic synapses (Santini et al., 2017). The GIT1/BPIX/ Rac1/PAK pathway can modulate $F$-actin and plays a crucial role in maintaining surface $\operatorname{GABA}(A) R$ levels and thus inhibits synaptic plasticity in the brain (Smith et al., 2014). PAK1 also plays key roles in synaptogenesis and spine morphogenesis by participating in ephrinB-EphB receptor signaling (Penzes et al., 2003). PAKs can also form a complex with pre/postsynaptic proteins to regulate synaptic plasticity. For example, PAKs can form a complex with Scribble, $\beta$-PIX, and GIT1, to regulate dendritic spine development via MLC (myosin II regulatory light chain). This complex can bind to NOS1AP, leading to Rac activation and altered spine morphology (Richier et al., 2010). Similarly, in Drosophila, Neto (neuropilin and tolloid-like)- $\beta$ can regulate the accumulation of PSD-associated PAKs by interacting with a large protein complex containing $\mathrm{dPIX}$ and Dock, which are crucial to the composition of neural circuits and the long-term plasticity of learning and memory at the neuromuscular junction (Ramos et al., 2015). However, most of the mechanisms underlying the relationship between PAKs and pre/postsynaptic proteins remain unclear. Figure 4 shows the detailed signaling pathways mediated by the PAK-related cytoskeleton in dendritic spines.

\section{Neuronal migration}

Neuronal migration from the birthplace to final location occurs in newly formed neurons and is critical for nervous system development (Guo et al., 2007; Marin et al., 2010). During the key stages of cortical development, group I PAKs are activated and expressed in migrating neurons, thereby regulating neuronal migration. For example, PAK1 controls the correct orientation and morphology as well as radial migration of neurons in the developing cerebral cortex (Zhong et al., 2003). PAK1 also promotes the formation of
Figure 3. The expression of PAKs in specific cell type and brain region. (A) Heatmap shows the cell number of each PAK in five specific cell types in the human brain using the R package "pheatmap". FB, fibroblast; MCPY, motor cortex pyramidal neurons; PBMC, peripheral blood mononuclear cells; TCPY, temporal cortex pyramidal neurons; SNDA, substantia nigra dopamine neurons. (B) Violin plotting shows the expression level of each Pak in seven cell types in the mouse brain. The Y-axis represents the expression level of cell type. (C) Dot plotting shows the mean expression and fraction levels of each $P a k$ in seven cell types in the mouse brain. (D)Violin plotting shows the expression level of each Pak in 20 specific cell types in the mouse brain using the Python package 'scanpy' versions 1.6.0 and 1.5.1. MSN, medium spiny neurons. (E) Dot plotting shows the mean expression and fraction levels of each Pak in 20 specific cell types in the mouse brain. MSN, medium spiny neurons.

polarized lamellipodia in migrating neurons and is essential for maintaining correct neocortical laminar organization (Causeret et al., 2009). Inhibition of PAK1 changes the morphology of migrating neurons, causing them to accumulate in the intermediate zone and deep layers of the cortex of mice (Causeret et al., 2009). The binding of the Ras prenylation sequence (CAAX-box) to the C-terminus of PAK1 is essential for its membrane activity (Jacobs et al., 2007). Overexpression of PAK1-CAAX caused neurons to reside in the intermediate zone of mice (Causeret et al., 2009). Notably, we found that PAK2 regulated the migration of neurons to the cortical plate in the developing cortex. PAK2 deficiency resulted in a dampened actin network and fewer neurons to migrate into the cortical plate (Wang et al., 2018).

RGCs (radial glial cells) are the principal subtype of neuronal progenitors and can produce most cortical neurons in the neocortex (Gotz and Barde, 2005). Zeb1 is expressed in RGCs during neocortical neurogenesis. It can bind to PAK3, which is relatively enriched in RGCs (Fig. 2B), and the methyltransferase PRMT5 to form a repressing complex that regulates radial migration and neuronal multipolar-bipolar transition in the developing mouse cortex (Liu et al., 2019). PAK3 is dramatically upregulated in Zeb1 knockout mice. Overexpression of PAK3 in wild-type cortical neurons showed the same phenotype as those in Zeb1 knockout mice, whereas Pak3 knockout rescued the abnormal migration of cortical neurons in Zeb1 knockout mice (Liu et al., 2019). Moreover, PAK3 expression is absent in MGE (medial ganglionic eminence)-derived migratory interneurons, but is upregulated as neurons differentiate (Cobos et al., 2007). PAK3 overexpression in the MGE can inhibit the tangential migration of interneurons to the neocortex (Cobos et al., 2007). In humans, a recent study highlighted 



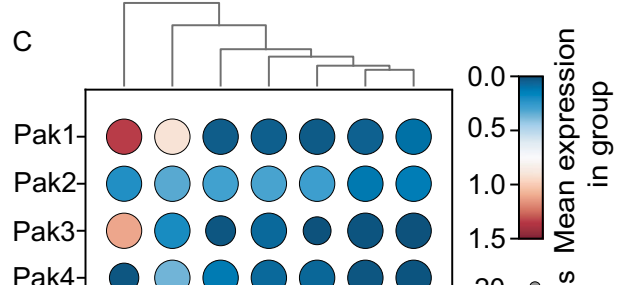

Pak4- $0000020-\frac{\omega}{\bar{N}} \widehat{0}$

Pak5- $\bigcirc \bigcirc \cdot 000040-0.00$ Pak6- $\bigcirc \bigcirc \bigcirc \bigcirc \bigcirc-6000$



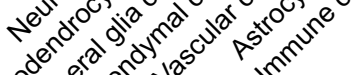

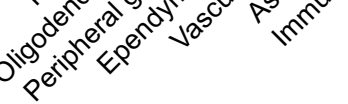

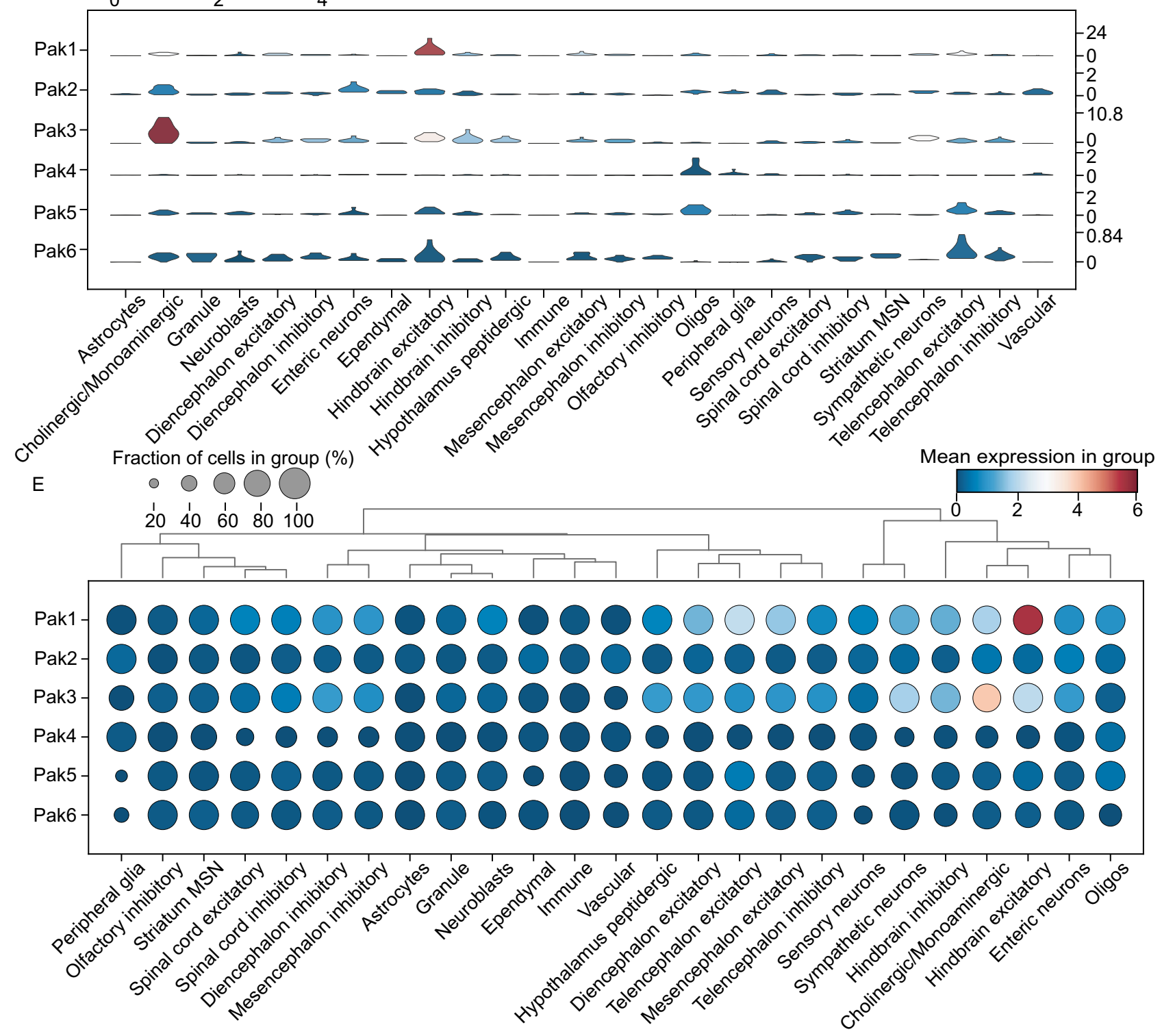




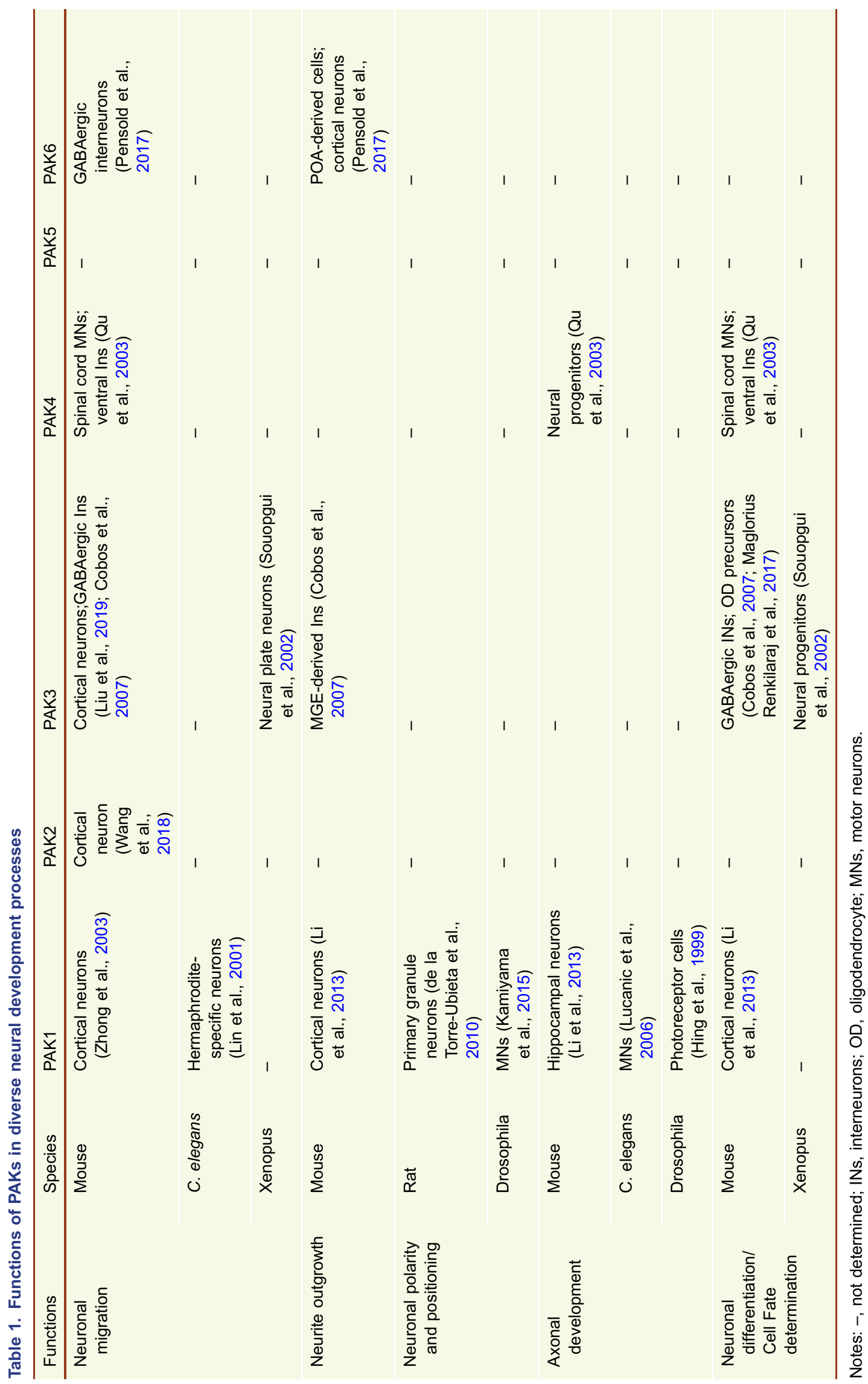


Table 2. PAK Mutations identified in patients with diverse neurological diseases

\begin{tabular}{|c|c|c|c|c|c|c|c|}
\hline & Chr. & Position & Alleles & Origin & Consequence & Diseases/Phenotypes & References \\
\hline \multirow[t]{4}{*}{ PAK1 } & \multirow[t]{4}{*}{ Chr11 } & 77336213 & $\mathrm{~T}>\mathrm{C}$ & \multirow[t]{2}{*}{ De novo } & \multirow[t]{2}{*}{ Missense } & \multirow{2}{*}{$\begin{array}{l}\text { ID with macrocephaly, } \\
\text { seizures, speech } \\
\text { delay }\end{array}$} & \multirow{2}{*}{$\begin{array}{l}\text { Harms et al., 2018; } \\
\text { Horn et al., } 2020\end{array}$} \\
\hline & & 77379288 & $\mathrm{~T}>\mathrm{C}$ & & & & \\
\hline & & 77474957 & $\begin{array}{r}\mathrm{G}>\mathrm{A} / \\
\mathrm{G}>\mathrm{T}\end{array}$ & \multirow[t]{2}{*}{-} & Intron variant & \multirow[t]{2}{*}{ SCZ } & \multirow[t]{2}{*}{ Jiang et al., 2017} \\
\hline & & 77322663 & $\begin{array}{r}A>C / \\
A>G\end{array}$ & & $\begin{array}{l}\text { 3' UTR } \\
\text { variant }\end{array}$ & & \\
\hline \multirow[t]{4}{*}{ PAK2 } & \multirow[t]{4}{*}{ Chr3 } & q29 & Deletion & $\begin{array}{l}\text { De novo/ } \\
\text { inherited }\end{array}$ & - & $\begin{array}{l}\text { 3q29 microdeletion } \\
\text { syndrome }\end{array}$ & Willatt et al., 2005 \\
\hline & & 196554151 & $C>T$ & De novo & Nonsense & \multirow[t]{3}{*}{ Autism } & \multirow[t]{3}{*}{ Wang et al., 2018} \\
\hline & & 196555271 & $C>T$ & $\begin{array}{l}\text { Maternal } \\
\text { inherited }\end{array}$ & Missense & & \\
\hline & & 196555271 & $G>A$ & $\begin{array}{l}\text { Paternal } \\
\text { inherited }\end{array}$ & & & \\
\hline \multirow[t]{5}{*}{ PAK3 } & \multirow[t]{5}{*}{ ChrX } & 111142119 & $C>T$ & - & \multirow[t]{2}{*}{ Missense } & \multirow[t]{5}{*}{ X-Linked MR, ID } & $\begin{array}{l}\text { Bienvenu et al., } \\
2000\end{array}$ \\
\hline & & 111194402 & $C>A$ & $\begin{array}{l}\text { Paternal } \\
\text { inherited }\end{array}$ & & & $\begin{array}{l}\text { Gedeon et al., } \\
2003\end{array}$ \\
\hline & & 111196488 & $C>T$ & - & Nonsense & & Allen et al., 1998 \\
\hline & & 111196570 & $G>C$ & \multirow[t]{2}{*}{ Inherited } & Missense & & Peippo et al., 2007 \\
\hline & & 111142200 & $A>G$ & & $\begin{array}{l}\text { Splice region } \\
\text { variant }\end{array}$ & & Rejeb et al., 2008 \\
\hline
\end{tabular}

Notes: -, not determined; MR, mental retardation; SCZ, schizophrenia; ID, intellectual disability; Chr, chromosome.

that the function of PAK3 in cell migration was associated with brain morphological changes in patients with intellectual disability and corpus callosum agenesis (Duarte et al., 2020).

Migration of GABAergic interneuron from their origin sites in the subpallium of the embryonic POA (preoptic area) to distant targets, such as the cerebral cortex, is a critical step in GABAergic interneuron development (Martini et al., 2009; Cooper, 2013). DNA methylation by DNMTs (DNA methyltransferases) is increased during the migration of active immature GABAergic interneurons (Pensold et al., 2017). DNMT1-positive cells showed significantly reduced levels of PAK6 expression, but cells expressing Pak6 were presented in later stages of maturation of postmigratory POA-fated neurons. Suppression of PAK6 by DNMT1 in POA-derived migrating GABAergic cells can prevent premature neuritogenesis and preserve their migratory morphology (Pensold et al., 2017). The results suggest that PAK6 is involved in the migration of GABAergic interneurons.

In addition to mammalian systems, PAKs regulate neural migrations in other species. For example, PAK3 can promote neuronal differentiation and migration in Xenopus laevis (Souopgui et al., 2002). PAK1 regulates the migration of HSNs (hermaphrodite-specific neurons) in Caenorhabditis elegans. The transcription factor DAF-16/FOXO, a known target of IGF-1 (insulin/insulin-like growth factor-1) signaling, regulates the posterior-to-anterior migration of HSNs in developing embryos (Henderson and Johnson, 2001; Lee et al., 2001; Lin et al., 2001). PAK1 is a downstream regulator of insulin/IGF-1-DAF-16 signaling during HSN migration (Kennedy et al., 2013). Considering PAK1 can help guide the migration of HSNs by remodeling the actin cytoskeleton and/ or regulating cell adhesion at hypodermal cell boundaries, the roles of PAK1 and FOXO in neuronal migration in higher organisms deserve further investigation (Kennedy et al., 2013). Whether other PAKs family members also function as the downstream of FOXO in neural migration remain to be investigated.

\section{Neurite outgrowth}

The movement and dynamics of growth cones, which guide the rate and direction of neurite outgrowth, are largely dependent on the assembly and reorganization of filopodia and lamellipodia (Brown et al., 2000). Rho GTPases, such as Rac1 and Cdc42, mediate the formation of lamellipodia and filopodia. As the main downstream effectors of Rac1 and Cdc42, PAKs play an important regulatory role in neurite growth in diverse species.

In the growth cones of neurons, PAK1 can interact with the NCAM (neural cell adhesion molecule), a member of the Ig superfamily, to induce the activation of the PAK1-LIMK1- 
cofilin pathway and promote cytoskeletal remodeling processes and filopodium mobility (Li et al., 2013). NCAM activation results in the dephosphorylation of PAK1 at Thr212 and hyperphosphorylation of PAK1 at Ser199/204 and Thr423, which are beneficial to the promotion of PAK1 activity and the formation of the PAK1/PIX/Cdc42 complex (Nikolic et al., 1998; Rashid et al., 2001; Parrini et al., 2009). After autophosphorylation, activated PAK1 phosphorylates LIMK at Thr508, which in turn phosphorylates cofilin at Ser3, followed by a reduction in its actin-depolymerizing activity ( $\mathrm{Li}$ et al., 2013). Increased actin polymerization promotes the movement of the growth cone and the generation of traction forces needed for neurite outgrowth (O'Donnell et al., 2009).

PAK3 contributes to the neurite outgrowth of cortical GABAergic and MGE-derived interneurons. Pak3 knockout inhibits neurite growth in cortical GABAergic interneurons during their migration (Cobos et al., 2007). Downregulation of PAK3 rescues the inordinate growth of neurites in postmigratory MGE-derived interneurons in $D / x 1 / 2$ mutants
(Cobos et al., 2007). PAK6 plays an essential role in cytoskeletal organization, thereby affecting cell shape, motility, and adhesion (Civiero et al., 2015). PAK6 promotes neurite outgrowth in postmitotic POA cells, which are characterized by a significantly high expression of PAK6. PAK6 also promotes neurite complexity and outgrowth in cortical projection neurons (Pensold et al., 2017).

\section{Neuronal differentiation}

Rac1 and Cdc42, which are downstream of NGF, are necessary for regulating various aspects of neuronal differentiation (Lamoureux et al., 1997; Yasui et al., 2001). As an effector of Rac1 and Cdc42, PAK1 controls the morphology and differentiation of cortical neurons via regulating cytoskeletal reorganization. PAK1 can also interact with NCAM to activate actin polymerization and promote neuronal differentiation (Li et al., 2013). In mice, PAK3 expression is upregulated as GABAergic interneurons differentiate.

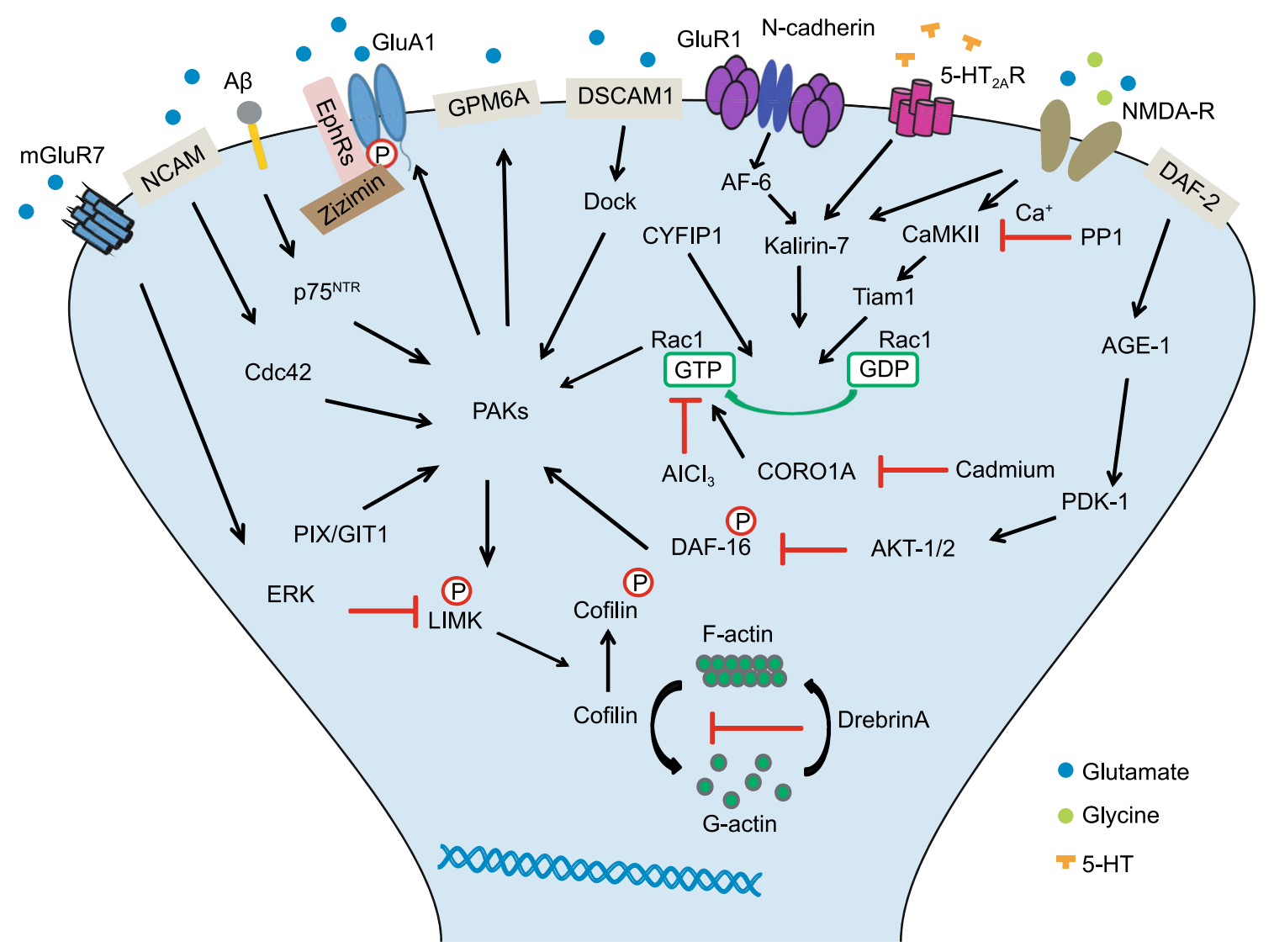

Figure 4. Graphic models of PAK signaling pathways in synaptic plasticity. The upstream activators of PAKs include Cdc42, Rac1, Dock, p75NTR, DAF-16 and PIX/GIT1 and the downstream factors contain GPM6A, GluA1 and LIMK (Henderson and Johnson, 2001; Kennedy et al., 2013; Li et al., 2013; Murata and Constantine-Paton, 2013; Gu et al., 2014; Hussain et al., 2015; Kamiyama et al., 2015; Ramos et al., 2015; Byrne et al., 2016; Kim et al., 2017; Santini et al., 2017; Leung et al., 2018; Feng et al., 2019). The main effect of PAKs is to regulate the formation of the cytoskeleton by activation of the LIMK-Cofilin pathway. The disruption of PAKs-related pathways is closely associated with diverse neurological disorders. 
High PAK3 expression is associated with increased neurite length and decreased neurite branching of cortical GABAergic interneurons in mice (Cobos et al., 2007). PAK3 is also highly expressed in OPCs (oligodendrocyte precursors) and shows decreased levels in mature oligodendrocytes (Maglorius Renkilaraj et al., 2017). Loss of Pak3 gene has reduced the density of differentiated oligodendrocytes in the developing white matter, suggesting that the expression of PAK3 in OPCs may be essential for the transformation from a proliferative to a differentiation stage (Maglorius Renkilaraj et al., 2017). Although the mechanism by which PAK3 promotes OPC differentiation remains unknown, one hypothesis is that PAK3 may control OPC differentiation by regulating the subcellular localization of LIMK1. This is because oligodendrocyte maturation depends on intracellular protein shuttling, and the accumulation of nuclear LIMK1 inhibits OPC differentiation (Gottle et al., 2015). In addition, Pak4-null embryos have shown defects in the differentiation of both spinal cord motor neurons and ventral interneurons. In particular, the lack of neuronal differentiation has been observed throughout the neural tube of Pak4-null embryos (Qu et al., 2003).

\section{Axonal development}

PAKs can also regulate axonal function and process, such as axonal transport, growth, and guidance. In Drosophila, PAK1-regulated actin cytoskeleton is essential for the axon guidance of photoreceptor cells (Hing et al., 1999). In mice, NCAM can interact with PAK1 and promote axonal growth in hippocampal neurons ( $\mathrm{Li}$ et al., 2013). Other adhesion molecules, such as DSCAM, also interact and activate PAK1 to regulate cell migration and neuronal differentiation and to induce axonal guidance (Rashid et al., 2001). PAK4 also plays an important role in axonal outgrowth and neuronal development by regulating actin cytoskeletal reorganization in neural progenitor cells (Jaffer and Chernoff, 2002; Qu et al., 2003). Pak4-deficient mouse embryos displayed impaired axonal outgrowth and neurons, including interneurons and spinal cord motor neurons, which failed to migrate to their proper locations in these mice (Qu et al., 2003).

The GEF domain of UNC-73, a Trio-like guanine nucleotide exchange factor, can specifically interact with Rac and activate UNC-73-Rac-PAK1 signaling, which has been found to contribute to the induction of motor commissural axons in C. elegans (Lucanic et al., 2006). In mice, TRIO, an UNC-73 mammalian homolog, can bind to DISC1, which results in the activation of TRIO-Rac1-PAK1 signaling that regulates axonal connectivity and guidance in the developing brain (Chen et al., 2011). Rac-PAK signaling also regulates the interaction between Schwann cells and axons in the peripheral nerves (Nakai et al., 2006). Before differentiation, cytoskeleton remodeling in Schwann cells is required for their expansion and migration towards the direction of axons (Nakai et al., 2006). Inhibition of Rac-PAK can restore neuronal interactions and promote aligned processes with neurites in Schwann cells (Nakai et al., 2006). Moreover, loss of MOCA (Modifier of Cell Adhesion), a guanine nucleotide exchange factor for Rac1 and a presenilin binding protein, results in altered PAK signaling, abnormal aggregation of neurofilament proteins, and disorganization of the axonal cytoskeleton, as well as axonal degeneration (Chen et al., 2005). In contrast, activation of MOCA-PAK-LIMK signaling can increase cofilin phosphorylation and have a regulatory effect on actin dynamics to prevent axonal degeneration (Chen et al., 2009). Axonal dysfunction, such as impaired axonal transport in the dystrophic axons and abnormal axonal growth and synaptogenesis, caused by abnormal gene expression or mutations in the Rac-PAK-related signaling pathway, have been observed in patients with schizophrenia, neurodegenerative diseases, and psychiatric disorders (Aston et al., 2005).

\section{Other functions of PAKs in nervous systems}

Neuronal polarity, such as axo-dendritic polarity, which allows the undifferentiated neurites to form the typical neuronal shape with short dendrites and a long axon, is critical to proper neuronal connectivity (Jan and Jan, 2003). FOXO transcription factors are widely activated in the developing mammalian brain and promote a switch from a nonpolarized state to a polarized morphology in neurons (Brunet et al., 1999; Hoekman et al., 2006). PAK1 is a direct target for FOXO transcription factors to control both actin and microtubule dynamics in neurons. In vivo knockdown of FOXO in the developing rat cerebellar cortex induced a robustly downregulation of PAK1 and impaired neuronal polarity in primary granule neurons (de la Torre-Ubieta et al., 2010). Moreover, PAK1 functions downstream of the Par polarity complex Par3/Par6/aPKC, which is also regulated by FOXO proteins (de la Torre-Ubieta et al., 2010). The FOXO-PAK1 pathway represents an important transcriptional mechanism that establishes neuronal polarity (de la Torre-Ubieta et al., 2010).

Precise positioning of dendritic branches is essential for establishing neuronal circuitry during development. Previous studies have shown that the Dscam1 (Down syndrome celladhesion molecule), the receptor of anterior corner cells in the motor neurons, can recruit Dock and PAK1 to the plasma membrane and define the precise positioning of dendritogenesis in Drosophila (Kamiyama et al., 2015). Similarly, in mammals, PAK1 interacts with the SH2-SH3 domain of the NCK protein, an ortholog of Drosophila Dock (Kamiyama et al., 2015). Pak1 mutation reduces the number of anterior corner cell dendritic branches and causes the misplacement of remaining branches (Kamiyama et al., 2015).

PAKs can regulate nerve conduction in non-neuronal cells. One of the few studies indicates that PAKs regulate the formation of the myelin sheath that wraps around axons in both the CNS (central nervous systems) (Maglorius Renkilaraj et al., 2017) and PNS (peripheral nervous systems) (Hu et al., 2016), the deficits of which can impair the nerve 
conduction of electrical impulses and have been reported in many neurological diseases. Oligodendrocytes are the myelin-forming cells of the CNS. One study showed that PAK3 was highly expressed at the OPC stage, and its expression decreased in differentiated and mature oligodendrocytes. Pak3 knockout mice displayed delayed OPC differentiation and consequently myelination defects in the corpus callosum (Maglorius Renkilaraj et al., 2017), suggesting that PAK3 is a new regulator of OPC differentiation. Schwann cells form the myelin in the PNS. Establishment of Schwann cell polarity includes the regulation of actin cytoskeleton. Schwannomas containing Schwann cells that show high Rac activity and disorganized cytoskeleton structure fail to interact with axons (Nakai et al., 2006). Moreover, increased F-actin levels correlated with enhanced PAK1 activity were found in a mouse model with disruption of myelin junctions in Schwann cells (Hu et al., 2016). The abnormal F-actin levels, myelin junction disruption, and nerve conduction failure in the mice can be completely rescued by pharmacological inhibition of PAK1 (Hu et al., 2016), suggesting a potential therapeutic approach for demyelinating diseases.

\section{NEUROLOGICAL DISEASES ASSOCIATED WITH PAK DYSFUNCTION}

Due to their crucial function in neural cytoskeleton regulation, PAKs play an indispensable role in brain development and behavior, and are involved in diverse neurological diseases, including both neurodevelopmental and neurodegenerative diseases. The identified mutations of PAKs in diverse neurological diseases have been summarized in Table 3.

\section{Autism spectrum disorders (ASDs)}

ASDs are a group of complex neurodevelopmental disorders characterized by abnormal social interaction and communication and restricted repetitive behavior (de la Torre-Ubieta et al., 2016). To date, approximately 1000 ASD-related genes have been added to the database (Pereanu et al., 2018), suggesting the high heterogeneity of this disease. Several recent studies have demonstrated the pathogenic mechanisms of PAK dysfunction and the impairment of its regulated-cytoskeletal dynamics in ASD etiology. For example, we found that PAK2 haploinsufficiency resulted in autism-related behaviors in both mice and humans. PAK2 dysfunction decreased the phosphorylation levels of LIMK1 and cofilin and their regulated actin networks related to ASDs (Wang et al., 2018). Functional annotations of PAK2regulated genes have shown that actin dysregulation represents a common pathophysiological mechanism in ASD (Wang et al., 2018). Moreover, Deficiency of Shank3, a known autism candidate gene that encoded synaptic scaffold, caused a strong in F-actin and NMDAR-mediated synaptic current by interfering with PAK signaling, which resulted in synaptic dysfunction and abnormal social behaviors in mice (Duffney et al., 2013). Notably, PAK1mediated actin dynamics can partially rescue ASD-related synaptic and behavioral phenotypes induced by Shank3 mutations in mice (Bozdagi et al., 2010; Peca et al., 2011). Recently, gain-of-function PAK1 mutations have also been identified in patients with neurodevelopmental phenotypes, including intellectual disability, macrocephaly, speech delay, seizures, and seizures (Harms et al., 2018; Horn et al., 2019). The finding suggests the direct contribution of PAK signaling to the pathology of the neurodevelopmental disease.

\section{Alzheimer's disease (AD)}

$A D$ is characterized by the accumulation of excessive $A \beta$ (amyloid beta) and tau proteins, which trigger a complex cascade resulting in synaptic loss and neurotransmitter deficiencies (Sivanesan et al., 2013). When $A \beta$ accumulates in the brain, it interacts with PAKs by binding to $\mathrm{p} 75^{\mathrm{NTR}}$ (a nerve growth factor receptor) to promote the activation of PAKs and phosphorylation of cofilin, eventually promoting NMDA excitotoxicity, a trigger of AD (Gu et al., 2014). A substantial loss of total PAKs has been detected in the cortex and hippocampus of patients with advanced $A D$ (Zhao et al., 2006; Ma et al., 2008; Nguyen et al., 2008). Moreover, aberrant translocation of PAK1 from cytoplasm to membrane and reduced postsynaptic PAK3 levels were also found in the brains of AD patients (Ma et al., 2008; Lauterborn et al., 2020), suggesting that PAK dysfunction impaired the stabilization of actin network and resulted in deficiencies in synaptic plasticity and behaviors. In the mouse model, PAK levels varied with age and were associated with the progression of AD (Ma et al., 2008). Loss of PAK expression specifically in the forebrain altered cortical synaptic morphology and prevented memory consolidation in mice (Dai et al., 2014). Considering the molecular pathways involved in PAK signaling are critical to synaptic function, PAKs are considered potential therapeutic targets for AD. Notably, although PAK inactivation decreased drebrin expression and impaired social recognition, it failed to further enhance $A \beta /$ tau pathology in AD mice (Arsenault et al., 2013). Thus, the reduction of PAKs is a consequence of the neuropathology of $A D$ rather than a cause; thus, therapeutic activation of PAKs may only have symptomatic benefits for brain function in AD (Arsenault et al., 2013).

\section{Mental retardation (MR)}

Fragile $X$ syndrome (FXS), the most common genetic form of $M R$, is caused by repeated CGG amplification of the FMR1 (fragile $X$ mental retardation 1) gene on the $X$ chromosome (O'Donnell and Warren, 2002; Darnell et al., 2011). Patients with FXS showed mental retardation, language disorder, appearance change, and behavioral disorder (Darnell and Klann, 2013). Similarly, an animal model of FXS exhibited 
multiple neuronal and behavioral abnormalities (Bhattacharya et al., 2012). Previous studies have consistently found that impaired RAC/PAK signaling and abnormal PAK expression were associated with abnormal dendritic spine architecture, neuronal development, and aberrant behaviors in Fmr1 mice (Chen et al., 2010; Santini et al., 2017). In Fmr1 mice, TBS (theta-burst stimulation) failed to activate and induce PAK phosphorylation in the spine, and newly formed actin filaments induced by theta stimulation remained unstable (Chen et al., 2010). Correspondingly, TBS inducedSchaffer-commissural fEPSP (fleld exciatatory postsynaptic potential) slopes were vulnerable to the treatment that disrupts dynamic actin filaments and showed a gradual decay in a short period, suggesting that LTP stabilization was abnormal in the mutants (Chen et al., 2010). Due to the lack of FMRP, CYFIP1 cannot inhibit Rac1 activity in Fmr1 mice, resulting in activation of the Rac1-PAK pathway and actin dynamic changes (Santini et al., 2017). Unusually elevated Rac1-PAK1 signaling results in a balance breakdown (Factin/G-actin) of the actin cytoskeleton and an immature spine phenotype in Fmr1 mice (Pyronneau et al., 2017). Notably, the morphological and behavioral phenotypes of Fmr1 mice are rescued either by expressing a dominantnegative form of PAK in the forebrain or by pharmacological inhibition of PAK (Hayashi et al., 2004; Hayashi et al., 2007; Dolan et al., 2013), suggesting the therapeutic potential of PAKs.

PAK3-related mental retardation also represents a rare cause of X-linked MR. Several loss of function and splice mutations in the PAK3 gene have been identified in different families of $X$-linked mental retardation with certain specific clinical features, such as microcephaly, mild to moderate mental retardation, oral motor dysfunction and aggressive behavior (Allen et al., 1998; Bienvenu et al., 2000; Gedeon et al., 2003; Peippo et al., 2007; Arsenault et al., 2013). Notably, clinical features usually observed in MR, such as autistic features, epilepsy or sleep disorder, have not been frequently observed in PAK3-related disorders (Rejeb et al., 2008), suggesting the distinguishable phenotypes of PAK3related MR from other X-linked MR syndromes.

\section{Schizophrenia}

Schizophrenia is a severe neuropsychiatric disorder with complex polygenic genetic patterns and affects approximately $1 \%$ of the world population (Lewis and Levitt, 2002; Ross et al., 2006). Patients with schizophrenia showed neurologic symptoms (delusions, hallucinations, and lack of motivation), and cognitive symptoms (poor executive functioning, trouble thinking, and working memory deficits) (Glantz and Lewis, 2001; Lewis et al., 2003; Sullivan et al., 2003). Several studies consistently found that the brain of patients with schizophrenia showed a reduction in dendritic spine density (Glantz and Lewis, 2001). Recent exome sequencing studies of de novo in schizophrenia trios and disruptive mutations in schizophrenia sporadic cases have revealed that genes related to activity-regulated cytoskeleton complex contributed to the high ranked genesets for

Table 3. Rodent models of Pak members

\begin{tabular}{|c|c|c|c|c|}
\hline Genotype & Features & Phenotypes & Impaired Signals & References \\
\hline Pak1 $1^{-1-}$ & $\begin{array}{l}\text { A part of the ATG exon and adjacent } \\
\text { upstream intronic sequence were replaced } \\
\text { by a PGK-NRG cassette }\end{array}$ & $\begin{array}{l}\text { Deficit in } E / l \\
\text { balance, deficit } \\
\text { in LTP }\end{array}$ & $\begin{array}{l}\downarrow \text { synaptic COX-2 } \\
\text { levels, } \uparrow \text { tonic } A E A \\
\text { signaling, } \downarrow p-C F L\end{array}$ & $\begin{array}{l}\text { Xia et al., 2016; } \\
\text { Asrar et al., } 2009\end{array}$ \\
\hline Pak2 $2^{-1-}$ & Pak2 knockout & Lethal at E8.5 & - & $\begin{array}{l}\text { C.H., Z. M. Jaffer } \\
\text { and J.C., } \\
\text { unpublished }\end{array}$ \\
\hline$P a k 2^{+/-}$ & $\begin{array}{l}\text { A poly-A and a PGK promoter were inserted } \\
\text { before the exon } 2 \text { of } P a k 2 \text { to terminate the } \\
\text { transcription }\end{array}$ & $\begin{array}{l}\text { Autism-related } \\
\text { behaviors }\end{array}$ & $\downarrow \mathrm{pLIMK} 1 / \mathrm{CFL}$ & Wang et al., 2018 \\
\hline $\mathrm{Pak3}^{-1-}$ & $\begin{array}{l}\text { A part of the coding and adjacent } \\
\text { downstream intronic sequence were } \\
\text { replaced by a PGK-NRG cassette }\end{array}$ & $\begin{array}{l}\text { Defects in LM, } \\
\text { myelin defects } \\
\text { in CC }\end{array}$ & - & $\begin{array}{l}\text { Meng et al., 2005; } \\
\text { Maglorius } \\
\text { Renkilaraj et al., } \\
2017\end{array}$ \\
\hline $\begin{array}{l}\text { Pak1 }{ }^{-1-} \text {; } \\
\text { Pak3 }^{-1-}\end{array}$ & DKO & $\begin{array}{l}\text { LM defects; } \\
\text { hyperactivity }\end{array}$ & $\downarrow p-C F L$ & Huang et al., 2011 \\
\hline Pak4 $4^{-/-}$ & $\begin{array}{l}\text { The exon } 1 \text { was replaced with a PGK-NPG } \\
\text { cassette flanked with } 5 \text { ' and } 3 \text { ' homology } \\
\text { regions. }\end{array}$ & $\begin{array}{l}\text { Lethal at E10.5; } \\
\text { heart and neural } \\
\text { tube defects }\end{array}$ & - & Qu et al., 2003 \\
\hline $\begin{array}{l}\text { Pak5 } 5^{-1-} \\
\text { Pak6 }\end{array}$ & DKO & $\begin{array}{l}\text { Impaired learning } \\
\text { and locomotion }\end{array}$ & - & $\begin{array}{l}\text { Nekrasova et al., } \\
2008\end{array}$ \\
\hline
\end{tabular}

Note: PGK-NRG, PGK-neomycin resistant gene; E/l, excitation and inhibition; LTP, long-term potentiation; CC, corpus callosum; LM, learning \& memory; E, embryonic day; p-CFL, phospho-cofilin; DKO, double knockout; -, not determined. 
schizophrenia (Fromer et al., 2014; Purcell et al., 2014), suggesting that dysfunction of actin skeletal dynamics contributed to the loss of dendritic spines in schizophrenia. In the ACC (anterior cingulate cortex) and DFC of patients with schizophrenia, PAK1 phosphorylation levels were reduced (Rubio et al., 2012). PAK1 phosphorylation inhibits MLCK (myosin light chain kinase), an enzyme that phosphorylates MLC (Sanders et al., 1999). However, the levels of pMLC (phosphorylated MLC), which is crucial for the structural actin cytoskeleton stability, were only increased in the ACC, and its expression in the DFC remained unchanged, suggesting that the PAK1 downstream pathways are distinguishingly affected in the cortical regions of patients with schizophrenia (Rubio et al., 2012). The increase in pMLC levels in the ACC has been linked to the shrinkage of the dendritic spine, suggesting a PAK1-related mechanism that regulates dendritic spine loss in schizophrenia (Rubio et al., 2012). Moreover, the schizophrenia risk gene DISC1 affects axonal guidance by activating the Rac-PAK signaling pathway (Kamiya et al., 2005). In patients with schizophrenia, abnormal expression of DISC1 can decrease PAK activity and cause defects in axonal guidance and neuronal connectivity (Chen et al., 2011). GIT1, a gene that regulates actin filament dynamics associated with schizophrenia, can bind to Rac/Cdc42 and interacts with PAKs. Most schizophrenia cases carrying GIT1 variants fail to induce PAK3 activation and GAD1, the key enzyme in GABA biosynthesis, in neurons (Kim et al., 2017), suggesting the contribution of PAK3 dysregulation in the synaptic deficits in schizophrenia.

\section{Parkinson's disease}

Parkinson's disease is a movement disorder characterized by the degeneration of dopaminergic neurons in the substantia nigra and reduction of dopamine in the striatum (Dauer and Przedborski, 2003). Among group II PAKs, PAK4 activity was significantly reduced in the substantia nigra of patients with and rodent models of Parkinson's disease (Won et al., 2016). Decline of PAK4 expression and activity in the human midbrain during aging can lead to a preparkinsonian state (Won et al., 2016). Overexpression of constitutively active PAK4 can protect dopaminergic neurons and preserve motor function (Won et al., 2016). PAK4 may promote the survival of dopaminergic neurons through the AKT signaling pathway (Kuijl et al., 2007; Tyagi et al., 2014). As an endogenous neuroprotective kinase, PAK4 and the PAK4-CRTC $1^{\text {S215 }}$-CREB pathway may be useful therapeutic targets for alleviating the symptoms of Parkinson's disease (Won et al., 2016). Moreover, PAK6 can bind to LRRK2 (leucine-rich repeat kinase 2), which is a cause of Parkinson's disease, and is required for LRRK2 to regulate neurite outgrowth (Civiero et al., 2015). The aberrant activation of PAK6 in the striata of patients with LRRK2-linked Parkinson's disease supports the role of PAK6 in the pathogenesis of Parkinson's disease (Civiero et al., 2015).

\section{Neurofibromatosis type 1}

NF1 (neurofibromatosis type 1) has an autosomal dominant pattern of inheritance (Barton and North, 2004; Noll et al., 2007). One altered copy of the NF1 gene can cause the disease (Pride et al., 2014). Over half of patients with NF1 have deficits in social behaviors and social information processing (Huijbregts et al., 2010; Huijbregts and de Sonneville, 2011), and around one-third of patients present with a severe clinical diagnosis of ASD (Garg et al., 2013; Walsh et al., 2013). Further analyses of patients with NF1 and social deficits showed that they also had problems with facial emotion recognition, a function linked to the human amygdala (Huijbregts et al., 2010; Garg et al., 2013; Lehtonen et al., 2013). In mice with a loss of a single NF1 allele, neurofibromin levels were reduced in several brain regions, including the hippocampus, amygdala, and frontal cortex, as observed in patients with NF1 (Costa et al., 2002; Cui et al., 2008; Molosh et al., 2014). Moreover, abnormal GABA and glutamate neurotransmission and MAPK pathways, disruptive LTP, and loss of expression of the synaptic protein disintegrin and Adam22 (Fukata et al., 2006) and Hsp70 (Molosh et al., 2014) were found in the amygdala of mice. Notably, although no obvious alterations in PAK activity or expression were observed, the social behavior deficits and amygdala disruptions in $\mathrm{Nf1}^{+/-}$ mice can be rescued by pharmacological blocking PAK1 activity in the amygdala or by the additional deletion of the Pak1 gene (Molosh et al., 2014), suggesting an indirect contribution of PAKs to the disease. Further study should investigate the molecular mechanism underlying the interaction between PAK1 and NF1 to better support the potential therapeutic role of PAKs in NF1.

\section{$3 q 29$ microdeletion syndrome}

$3 q 29$ microdeletion syndrome is a rare chromosomal disorder caused by the deletion at the long (q) arm of chromosome 3. Approximately $80 \%-99 \%$ of people with the $3 q 29$ microdeletion have mild to moderate intellectual disability. They also have an increased risk of behavioral or psychiatric disorders, including autism, bipolar disorder, and schizophrenia (Willatt et al., 2005). The most frequently deleted segment of chromosome in patients with $3 q 29$ microdeletion contains about 20 genes (Quintero-Rivera et al., 2010). De novo copy-number variations that contain PAK2 were found in children with 3q29 microdeletion syndrome (Willatt et al., 2005). Notably, our study also found another de novo copy-number deletion containing the PAK2 gene in a patient with ASD (Wang et al., 2018), suggesting the contribution of $P A K 2$ gene deletion in 3q29 microdeletion syndrome.

\section{CONCLUSIONS AND PERSPECTIVES}

PAKs are widely present in neuronal and non-neuronal cells in the central and peripheral nerve system. In neuronal cells, 
each PAKIPak shows different expression pattern thus exerts differential roles during brain development. Paks are also highly expressed in non-neuronal cells, such as oligodendrocytes, astrocytes, and peripheral glial cells. In particular, PAKs in oligodendrocytes have found to regulate myelin sheath formation to contribute to nerve conduction. Thus, whether the PAK-regulated cytoskeleton in non-neuronal cells (such as oligodendrocyte and astrocytes) affects neuronal function and how it contributes to neurodevelopment and brain function requires further investigation.

PAKs regulate synaptic plasticity by regulating both spine morphology and synaptic transmission/trafficking. PAKs can also regulate diverse neural functions and processes and are involved in broad neural activities in the brain. PAKs participate in various signaling pathways related to cytoskeletal remodeling and thus are involved in the molecular pathology of neurological disorders at different neurodevelopmental stages. PAKs thus have been found to play both direct (such as ASD, MR and $A D$ ) and indirect roles (NF1) in the pathology of neurological diseases. Although some of the molecular mechanisms remain unknown, PAKs, possessing specific small-molecule inhibitors in cancer treatment, also represent potential therapeutic targets of neurological diseases involving PAK dysfunction, which necessitates further investigation. Moreover, considering the differential roles of PAKs in neural function, small molecules specific for each PAK rather than a group of PAKs may provide more precise and accurate improvement for PAK-related neurological diseases.

\section{ACKNOWLEDGEMENTS}

This work was supported by the National Natural Science Foundation of China (Nos. 32070590 and 31871191), and the Guangdong Key Project in the "development of new tools for diagnosis and treatment of Autism" (2018B030335001).

\section{ABBREVIATIONS}

$A C C$, anterior cingulate cortex; AD, Alzheimer's disease; AgRP, agouti-related peptide; AID, autoinhibitory domain; AMPK, AMPactivated protein kinase; AMPAR, AMPA receptor; ASD, Autism spectrum disorders; $A \beta$, amyloid beta; CNS, central nervous system; COX-2, cyclooxygenase-2; DFC, dorsolateral prefrontal cortex; DNMTs, DNA methyltransferases; Dscam1, down syndrome celladhesion molecule; F-actin, filamentous actin; FB, fibroblast; FMR1, fragile $X$ mental retardation 1 ; fEPSP, fleld exciatatory postsynaptic potential; FXS, fragile X syndrome; GIT1, G protein-coupled receptor kinase interacting protein ArfGAP1; GRB2, growth factor receptorbound protein 2; HBT, Human Brain Transcriptome; HSNs, hermaphrodite-specific neurons; IGF-1, insulin-like growth factor-1; LIMK1/2, LIM motif-containing protein kinases 1 and 2; LRRK2, leucine-rich repeat kinase 2; LTD, long-term depression; LTP, longterm potentiation; MCPY, motor cortex pyramidal neurons; MGE, medial ganglionic eminence; MLC, myosin II regulatory light chain; MLCK, myosin light chain kinase; MOCA, modifier of cell adhesion; MR, Mental retardation; mEPSCs, miniature excitatory postsynaptic currents; NCAM, neural cell adhesion molecule; Neto, neuropilin and tolloid-like; NCK1, NCK adaptor protein 1; NF1, neurofibromatosis type 1; OPCs, oligodendrocyte precursors; PAKs, p21-activated kinases; PBD, p21-binding domain; PBMC, peripheral blood mononuclear cells; PBR, polybasic region; PNS, peripheral nervous systems; POA, preoptic area; PIX, PAK-interacting exchange factor; pMLC, phosphorylated MLC; RGCs, radial glial cells; SNDA, substantia nigra dopamine neurons; TBS, theta-burst stimulation; TCPY, temporal cortex pyramidal neurons.

\section{COMPLIANCE WITH ETHICS GUIDELINES}

Kaifan Zhang, Yan Wang, Tianda Fan, Cheng Zeng, and Zhong Sheng Sun declare no potential conflicts of interest with respect to the research, authorship, and/or publication of this article. This article does not contain any studies with human or animal subjects performed by the any of the authors.

\section{OPEN ACCESS}

This article is licensed under a Creative Commons Attribution 4.0 International License, which permits use, sharing, adaptation, distribution and reproduction in any medium or format, as long as you give appropriate credit to the original author(s) and the source, provide a link to the Creative Commons licence, and indicate if changes were made. The images or other third party material in this article are included in the article's Creative Commons licence, unless indicated otherwise in a credit line to the material. If material is not included in the article's Creative Commons licence and your intended use is not permitted by statutory regulation or exceeds the permitted use, you will need to obtain permission directly from the copyright holder. To view a copy of this licence, visit http:// creativecommons.org/licenses/by/4.0/.

\section{REFERENCES}

Allen KM, Gleeson JG, Bagrodia S, Partington MW, MacMillan JC, Cerione RA, Mulley JC, Walsh CA (1998) PAK3 mutation in nonsyndromic X-linked mental retardation. Nat Genet 20:25-30

Arber S, Barbayannis FA, Hanser H, Schneider C, Stanyon CA, Bernard O, Caroni P (1998) Regulation of actin dynamics through phosphorylation of cofilin by LIM-kinase. Nature 393:805-809

Arias-Romero LE, Chernoff J (2008) A tale of two Paks. Biol Cell 100:97-108

Arsenault D, Dal-Pan A, Tremblay C, Bennett DA, Guitton MJ, De Koninck Y, Tonegawa S, Calon F (2013) PAK inactivation impairs social recognition in 3xTg-AD Mice without increasing brain deposition of tau and Abeta. J Neurosci 33:10729-10740

Asrar S, Meng Y, Zhou Z, Todorovski Z, Huang WW, Jia Z (2009) Regulation of hippocampal long-term potentiation by $\mathrm{p} 21$-activated protein kinase 1 (PAK1). Neuropharmacology 56:73-80

Aston C, Jiang L, Sokolov BP (2005) Transcriptional profiling reveals evidence for signaling and oligodendroglial abnormalities in the temporal cortex from patients with major depressive disorder. Mol Psychiatry. 10:309-322 
Banko MR, Allen JJ, Schaffer BE, Wilker EW, Tsou P, White JL, Villén J, Wang B, Kim SR, Sakamoto K et al (2011) Chemical genetic screen for AMPKa2 substrates uncovers a network of proteins involved in mitosis. Mol Cell 44:878-892

Barton B, North K (2004) Social skills of children with neurofibromatosis type 1. Dev Med Child Neurol 46:553-563

Bhattacharya A, Kaphzan H, Alvarez-Dieppa AC, Murphy JP, Pierre P, Klann E (2012) Genetic removal of p70 S6 kinase 1 corrects molecular, synaptic, and behavioral phenotypes in fragile $X$ syndrome mice. Neuron 76:325-337

Bienvenu T, des Portes V, McDonell N, Carrié A, Zemni R, Couvert P, Ropers HH, Moraine C, van Bokhoven H, Fryns JP et al (2000) Missense mutation in PAK3, R67C, causes X-linked nonspecific mental retardation. Am J Med Genet 93:294-298

Bozdagi O, Sakurai T, Papapetrou D, Wang X, Dickstein DL, Takahashi N, Kajiwara Y, Yang M, Katz AM, Scattoni ML et al (2010) Haploinsufficiency of the autism-associated Shank3 gene leads to deficits in synaptic function, social interaction, and social communication. Mol Autism 1:15

Brown MD, Cornejo BJ, Kuhn TB, Bamburg JR (2000) Cdc42 stimulates neurite outgrowth and formation of growth cone filopodia and lamellipodia. J Neurobiol 43:352-364

Brunet A, Bonni A, Zigmond MJ, Lin MZ, Juo P, Hu LS, Anderson MJ, Arden KC, Blenis J, Greenberg ME (1999) Akt promotes cell survival by phosphorylating and inhibiting a Forkhead transcription factor. Cell 96:857-868

Byrne KM, Monsefi N, Dawson JC, Degasperi A, Bukowski-Wills JC, Volinsky N, Dobrzynski M, Birtwistle MR, Tsyganov MA, Kiyatkin A et al (2016) Bistability in the Rac1, PAK, and RhoA Signaling Network Drives Actin Cytoskeleton Dynamics and Cell Motility Switches. Cell Syst. 2:38-48

Causeret F, Terao M, Jacobs T, Nishimura YV, Yanagawa Y, Obata K, Hoshino M, Nikolic M (2009) The p21-activated kinase is required for neuronal migration in the cerebral cortex. Cereb Cortex 19:861-875

Chen LY, Rex CS, Babayan AH, Kramár EA, Lynch G, Gall CM, Lauterborn JC (2010) Physiological activation of synaptic Rac>PAK (p-21 activated kinase) signaling is defective in a mouse model of fragile X syndrome. J Neurosci 30:10977-10984

Chen Q, Chen TJ, Letourneau PC, Costa Lda F, Schubert D (2005) Modifier of cell adhesion regulates $\mathrm{N}$-cadherin-mediated cell-cell adhesion and neurite outgrowth. J Neurosci 25:281-290

Chen Q, Peto CA, Shelton GD, Mizisin A, Sawchenko PE, Schubert D (2009) Loss of modifier of cell adhesion reveals a pathway leading to axonal degeneration. J Neurosci 29:118-130

Chen SY, Huang PH, Cheng HJ (2011) Disrupted-in-Schizophrenia 1-mediated axon guidance involves TRIO-RAC-PAK small GTPase pathway signaling. Proc Natl Acad Sci U S A. 108:5861-5866

Chenette EJ, Mitin NY, Der CJ (2006) Multiple sequence elements facilitate Chp Rho GTPase subcellular location, membrane association, and transforming activity. Mol Biol Cell 17:31083121

Civiero L, Cirnaru MD, Beilina A, Rodella U, Russo I, Belluzzi E, Lobbestael E, Reyniers L, Hondhamuni G, Lewis PA et al (2015) Leucine-rich repeat kinase 2 interacts with p21-activated kinase 6 to control neurite complexity in mammalian brain. J Neurochem 135:1242-1256

Cobos I, Borello U, Rubenstein JL (2007) Dlx transcription factors promote migration through repression of axon and dendrite growth. Neuron 54:873-888

Cooper JA (2013) Cell biology in neuroscience: mechanisms of cell migration in the nervous system. J Cell Biol 202:725-734

Costa RM, Federov NB, Kogan JH, Murphy GG, Stern J, Ohno M, Kucherlapati R, Jacks T, Silva AJ (2002) Mechanism for the learning deficits in a mouse model of neurofibromatosis type 1. Nature 415:526-530

Cui Y, Costa RM, Murphy GG, Elgersma Y, Zhu Y, Gutmann DH, Parada LF, Mody I, Silva AJ (2008) Neurofibromin regulation of ERK signaling modulates GABA release and learning. Cell 135:549-560

Dai X, Iwasaki H, Watanabe M, Okabe S (2014) Dlx1 transcription factor regulates dendritic growth and postsynaptic differentiation through inhibition of neuropilin-2 and PAK3 expression. Eur $\mathrm{J}$ Neurosci 39:531-547

Daniels RH, Bokoch GM (1999) p21-activated protein kinase: a crucial component of morphological signaling? Trends Biochem Sci 24:350-355

Darnell JC, Klann E (2013) The translation of translational control by FMRP: therapeutic targets for FXS. Nat Neurosci 16:1530-1536

Darnell JC, Van Driesche SJ, Zhang C, Hung KY, Mele A, Fraser CE, Stone EF, Chen C, Fak JJ, Chi SW et al (2011) FMRP stalls ribosomal translocation on mRNAs linked to synaptic function and autism. Cell 146:247-261

Dauer W, Przedborski S (2003) Parkinson's disease: mechanisms and models. Neuron 39:889-909

de la Torre-Ubieta L, Gaudilliere B, Yang Y, Ikeuchi Y, Yamada T, DiBacco S, Stegmuller J, Schuller U, Salih DA, Rowitch D et al (2010) A FOXO-Pak1 transcriptional pathway controls neuronal polarity. Genes Dev 24:799-813

de la Torre-Ubieta L, Won H, Stein JL, Geschwind DH (2016) Advancing the understanding of autism disease mechanisms through genetics. Nat Med 22:345-361

Dolan BM, Duron SG, Campbell DA, Vollrath B, Shankaranarayana Rao BS, Ko HY, Lin GG, Govindarajan A, Choi SY, Tonegawa S (2013) Rescue of fragile $X$ syndrome phenotypes in Fmr1 KO mice by the small-molecule PAK inhibitor FRAX486. Proc Natl Acad Sci U S A. 110:5671-5676

Dong X, Liao Z, Gritsch D, Hadzhiev Y (2018) Enhancers active in dopamine neurons are a primary link between genetic variation and neuropsychiatric disease. Nat Neurosci 21:1482-1492

Duarte K, Heide S, Poea-Guyon S, Rousseau V, Depienne C, Rastetter A, Nava C, Attie-Bitach T, Razavi F, Martinovic J et al (2020) PAK3 mutations responsible for severe intellectual disability and callosal agenesis inhibit cell migration. Neurobiol Dis 136:104709

Dubos A, Combeau G, Bernardinelli Y, Barnier JV, Hartley O, Gaertner H, Boda B, Muller D (2012) Alteration of synaptic network dynamics by the intellectual disability protein PAK3. J Neurosci 32:519-527

Duffney LJ, Wei J, Cheng J, Liu W, Smith KR, Kittler JT, Yan Z (2013) Shank3 deficiency induces NMDA receptor hypofunction via an actin-dependent mechanism. J Neurosci 33:15767-15778 
Eswaran J, Soundararajan M, Kumar R, Knapp S (2008) UnPAKing the class differences among p21-activated kinases. Trends Biochem Sci 33:394-403

Feng J, Chen S, Wang Y, Liu Q, Yang M, Li X, Nie C, Qin J, Chen H, Yuan $X$ et al (2019) Maternal exposure to cadmium impairs cognitive development of male offspring by targeting the Coronin1a signaling pathway. Chemosphere 225:765-774

Fromer M, Pocklington AJ, Kavanagh DH, Williams HJ, Dwyer S, Gormley P, Georgieva L, Rees E, Palta P, Ruderfer DM et al (2014) De novo mutations in schizophrenia implicate synaptic networks. Nature 506:179-184

Fukata Y, Adesnik H, Iwanaga T, Bredt DS, Nicoll RA, Fukata M (2006) Epilepsy-related ligand/receptor complex LGI1 and ADAM22 regulate synaptic transmission. Science 313:17921795

Gao J, Ha BH, Lou HJ, Morse EM, Zhang R, Calderwood DA, Turk BE, Boggon TJ (2013) Substrate and inhibitor specificity of the type II p21-activated kinase, PAK6. PLoS ONE 8:e77818

Garg S, Green J, Leadbitter K, Emsley R, Lehtonen A, Evans DG, Huson SM (2013) Neurofibromatosis type 1 and autism spectrum disorder. Pediatrics 132:e1642-e1648

Gedeon AK, Nelson J, Gécz J, Mulley JC (2003) X-linked mild nonsyndromic mental retardation with neuropsychiatric problems and the missense mutation A365E in PAK3. Am J Med Genet A 120a:509-517

Glantz LA, Lewis DA (2001) Dendritic spine density in schizophrenia and depression. Arch Gen Psychiatry 58:203

Gottle P, Sabo JK, Heinen A, Venables G, Torres K (2015) Oligodendroglial maturation is dependent on intracellular protein shuttling. J Neurosci 35:906-919

Gotz M, Barde YA (2005) Radial glial cells defined and major intermediates between embryonic stem cells and CNS neurons. Neuron 46:369-372

Gu Z, Cheng J, Zhong P, Qin L, Liu W, Yan Z (2014) Abeta selectively impairs mGluR7 modulation of NMDA signaling in basal forebrain cholinergic neurons: implication in Alzheimer's disease. J Neurosci 34:13614-13628

Guo D, Tan YC, Wang D, Madhusoodanan KS, Zheng Y, Maack T, Zhang JJ, Huang XY (2007) A Rac-cGMP signaling pathway. Cell. 128:341-355

$\mathrm{Ha} \mathrm{BH}$, Boggon TJ (2018) CDC42 binds PAK4 via an extended GTPase-effector interface. Proc Natl Acad Sci U S A. 115:531536

Ha BH, Davis MJ, Chen C, Lou HJ, Gao J, Zhang R, Krauthammer M, Halaban R, Schlessinger J, Turk BE et al (2012) Type II p21activated kinases (PAKs) are regulated by an autoinhibitory pseudosubstrate. Proc Natl Acad Sci U S A. 109:16107-16112

Harms FL, Kloth K, Bley A, Denecke J, Santer R, Lessel D, Hempel M, Kutsche K (2018) Activating Mutations in PAK1, Encoding p21-Activated Kinase 1, Cause a Neurodevelopmental Disorder. Am J Hum Genet 103:579-591

Hayashi-Takagi A, Araki Y, Nakamura M, Vollrath B, Duron SG, Yan Z, Kasai H, Huganir RL, Campbell DA, Sawa A (2014) PAKs inhibitors ameliorate schizophrenia-associated dendritic spine deterioration in vitro and in vivo during late adolescence. Proc Natl Acad Sci U S A. 111:6461-6466
Hayashi ML, Choi SY, Rao BS, Jung HY, Lee HK, Zhang D, Chattarji S, Kirkwood A, Tonegawa S (2004) Altered cortical synaptic morphology and impaired memory consolidation in forebrainspecific dominant-negative PAK transgenic mice. Neuron 42:773-787

Hayashi ML, Rao BS, Seo JS, Choi HS, Dolan BM, Choi SY, Chattarji S, Tonegawa S (2007) Inhibition of p21-activated kinase rescues symptoms of fragile $X$ syndrome in mice. Proc Natl Acad Sci U S A. 104:11489-11494

Henderson ST, Johnson TE (2001) daf-16 integrates developmental and environmental inputs to mediate aging in the nematode Caenorhabditis elegans. Curr Biol 11:1975-1980

Hing H, Xiao J, Harden N, Lim L, Zipursky SL (1999) Pak functions downstream of Dock to regulate photoreceptor axon guidance in Drosophila. Cell 97:853-863

Hoekman MF, Jacobs FM, Smidt MP, Burbach JP (2006) Spatial and temporal expression of FoxO transcription factors in the developing and adult murine brain. Gene Expr Patterns 6:134-140

Horn S, Au M, Basel-Salmon L, Bayrak-Toydemir P, Chapin A, Cohen L, Elting MW, Graham JM, Gonzaga-Jauregui C, Konen O et al (2019) De novo variants in PAK1 lead to intellectual disability with macrocephaly and seizures. Brain 142:3351-3359

Hu B, Arpag S, Zhang X, Möbius W, Werner H, Sosinsky G, Ellisman $M$, Zhang $Y$, Hamilton A, Chernoff $J$ et al (2016) Tuning PAK Activity to Rescue Abnormal Myelin Permeability in HNPP. PLoS Genet 12:e1006290

Huang W, Zhou Z, Asrar S, Henkelman M, Xie W, Jia Z (2011) p21Activated kinases 1 and 3 control brain size through coordinating neuronal complexity and synaptic properties. Mol Cell Biol 31:388-403

Huijbregts S, Jahja R, De Sonneville L, de Breij S, Swaab-Barneveld $H$ (2010) Social information processing in children and adolescents with neurofibromatosis type 1. Dev Med Child Neurol 52:620-625

Huijbregts SC, de Sonneville LM (2011) Does cognitive impairment explain behavioral and social problems of children with neurofibromatosis type 1? Behav Genet 41:430-436

Hussain NK, Thomas GM, Luo J, Huganir RL (2015) Regulation of AMPA receptor subunit GluA1 surface expression by PAK3 phosphorylation. Proc Natl Acad Sci U S A. 112:E5883-E5890

Jacobs T, Causeret F, Nishimura YV, Terao M, Norman A, Hoshino M, Nikolic M (2007) Localized activation of p21-activated kinase controls neuronal polarity and morphology. J Neurosci 27:86048615

Jaffer ZM, Chernoff J (2002) p21-activated kinases: three more join the Pak. Int J Biochem Cell Biol 34:713-717

Jan YN, Jan LY (2003) The control of dendrite development. Neuron 40:229-242

Johnson MB, Kawasawa YI, Mason CE, Krsnik Z, Coppola G, Bogdanović D, Geschwind DH, Mane SM, State MW, Sestan N (2009) Functional and evolutionary insights into human brain development through global transcriptome analysis. Neuron 62:494-509

Kamiya A, Kubo K, Tomoda T, Takaki M, Youn R, Ozeki Y, Sawamura N, Park U, Kudo C, Okawa M et al (2005) A schizophrenia-associated mutation of DISC1 perturbs cerebral cortex development. Nat Cell Biol 7:1167-1178 
Kamiyama D, McGorty R, Kamiyama R, Kim MD, Chiba A, Huang B (2015) Specification of Dendritogenesis Site in Drosophila aCC Motoneuron by Membrane Enrichment of Pak1 through Dscam1. Dev Cell 35:93-106

Kang HJ, Kawasawa YI, Cheng F, Zhu Y, Xu X, Li M, Sousa AM, Pletikos M, Meyer KA, Sedmak $G$ et al (2011) Spatio-temporal transcriptome of the human brain. Nature 478:483-489

Kennedy LM, Pham SC, Grishok A (2013) Nonautonomous regulation of neuronal migration by insulin signaling, DAF-16/FOXO, and PAK-1. Cell Rep. 4:996-1009

Kim MJ, Biag J, Fass DM, Lewis MC, Zhang Q, Fleishman M, Gangwar SP, Machius M, Fromer M, Purcell SM et al (2017) Functional analysis of rare variants found in schizophrenia implicates a critical role for GIT1-PAK3 signaling in neuroplasticity. Mol Psychiatry. 22:417-429

Knaus UG, Bokoch GM (1998) The p21Rac/Cdc42-activated kinases (PAKs). Int J Biochem Cell Biol 30:857-862

Kong D, Dagon Y, Campbell JN, Guo Y, Yang Z, Yi X, Aryal P, Wellenstein K, Kahn BB, Sabatini BL et al (2016) A Postsynaptic AMPK $\rightarrow$ p21-Activated Kinase Pathway Drives Fasting-Induced Synaptic Plasticity in AgRP Neurons. Neuron 91:25-33

Kreis P, Barnier JV (2009) PAK signalling in neuronal physiology. Cell Signal 21:384-393

Kuijl C, Savage ND, Marsman M, Tuin AW, Janssen L, Egan DA, Ketema M, van den Nieuwendijk R, van den Eeden SJ, Geluk A et al (2007) Intracellular bacterial growth is controlled by a kinase network around PKB/AKT1. Nature 450:725-730

Lamoureux P, Altun-Gultekin ZF, Lin C, Wagner JA, Heidemann SR (1997) Rac is required for growth cone function but not neurite assembly. J Cell Sci 110(Pt 5):635-641

Lauterborn JC, Cox CD, Chan SW, Vanderklish PW, Lynch G, Gall CM (2020) Synaptic actin stabilization protein loss in Down syndrome and Alzheimer disease. Brain Pathol 30:319-331

Lee RY, Hench J, Ruvkun G (2001) Regulation of C. elegans DAF16 and its human ortholog FKHRL1 by the daf-2 insulin-like signaling pathway. Curr Biol 11:1950-1957

Lehtonen A, Howie E, Trump D, Huson SM (2013) Behaviour in children with neurofibromatosis type 1: cognition, executive function, attention, emotion, and social competence. Dev Med Child Neurol 55:111-125

Lei M, Lu W, Meng W, Parrini MC, Eck MJ, Mayer BJ, Harrison SC (2000) Structure of PAK1 in an autoinhibited conformation reveals a multistage activation switch. Cell 102:387-397

Lein ES, Hawrylycz MJ, Ao N, Ayres M, Bensinger A, Bernard A, Boe AF, Boguski MS, Brockway KS, Byrnes EJ et al (2007) Genome-wide atlas of gene expression in the adult mouse brain. Nature 445:168-176

Leung C, Cao F, Nguyen R, Joshi K, Aqrabawi AJ, Xia S, Cortez MA, Snead OC 3rd, Kim JC, Jia Z (2018) Activation of Entorhinal Cortical Projections to the Dentate Gyrus Underlies Social Memory Retrieval. Cell Rep. 23:2379-2391

Lewis DA, Glantz LA, Pierri JN, Sweet RA (2003) Altered cortical glutamate neurotransmission in schizophrenia: evidence from morphological studies of pyramidal neurons. Ann N Y Acad Sci 1003:102-112

Lewis DA, Levitt P (2002) Schizophrenia as a disorder of neurodevelopment. Annu Rev Neurosci 25:409-432
Li S, Leshchyns'ka I, Chernyshova Y, Schachner M, Sytnyk V (2013) The neural cell adhesion molecule (NCAM) associates with and signals through p21-activated kinase 1 (Pak1). J Neurosci 33:790-803

Lin K, Hsin H, Libina N, Kenyon C (2001) Regulation of the Caenorhabditis elegans longevity protein DAF-16 by insulin/IGF1 and germline signaling. Nat Genet 28:139-145

Liu J, Liu Y, Shao J, Li Y, Qin L, Shen H, Xie Y, Xia W (2019) Zeb1 is important for proper cleavage plane orientation of dividing progenitors and neuronal migration in the mouse neocortex. Cell Death Differ 26:2479-2492

Lucanic M, Kiley M, Ashcroft N, L'Etoile N, Cheng HJ (2006) The Caenorhabditis elegans P21-activated kinases are differentially required for UNC-6/netrin-mediated commissural motor axon guidance. Development. 133:4549-4559

Ma QL, Yang F, Calon F, Ubeda OJ, Hansen JE, Weisbart RH, Beech W, Frautschy SA, Cole GM (2008) p21-activated kinaseaberrant activation and translocation in Alzheimer disease pathogenesis. J Biol Chem 283:14132-14143

Maglorius Renkilaraj MRL, Baudouin L, Wells CM, Doulazmi M, Wehrle R, Cannaya V, Bachelin C, Barnier JV, Jia Z, Nait Oumesmar B et al (2017) The intellectual disability protein PAK3 regulates oligodendrocyte precursor cell differentiation. Neurobiol Dis $98: 137-148$

Manser E, Leung T, Salihuddin H, Zhao ZS, Lim L (1994) A brain serine/threonine protein kinase activated by $\mathrm{Cdc} 42$ and Rac1. Nature 367:40-46

Marin O, Valiente M, Ge X, Tsai LH (2010) Guiding neuronal cell migrations. Cold Spring Harb Perspect Biol. 2:a001834

Martini FJ, Valiente M, Lopez Bendito G, Szabo G, Moya F, Valdeolmillos M, Marin O (2009) Biased selection of leading process branches mediates chemotaxis during tangential neuronal migration. Development. 136:41-50

Meng J, Meng Y, Hanna A, Janus C, Jia Z (2005) Abnormal longlasting synaptic plasticity and cognition in mice lacking the mental retardation gene Pak3. J Neurosci 25:6641-6650

Molosh Al, Johnson PL, Spence JP, Arendt D, Federici LM, Bernabe C, Janasik SP, Segu ZM, Khanna R, Goswami C et al (2014) Social learning and amygdala disruptions in Nf1 mice are rescued by blocking p21-activated kinase. Nat Neurosci 17:1583-1590

Murata Y, Constantine-Paton M (2013) Postsynaptic density scaffold SAP102 regulates cortical synapse development through EphB and PAK signaling pathway. J Neurosci 33:5040-5052

Nakai Y, Zheng Y, MacCollin M, Ratner N (2006) Temporal control of Rac in Schwann cell-axon interaction is disrupted in NF2-mutant schwannoma cells. J Neurosci 26:3390-3395

Nekrasova T, Jobes ML, Ting JH, Wagner GC, Minden A (2008) Targeted disruption of the Pak5 and Pak6 genes in mice leads to deficits in learning and locomotion. Dev Biol 322:95-108

Nguyen TV, Galvan V, Huang W, Banwait S, Tang H, Zhang J, Bredesen DE (2008) Signal transduction in Alzheimer disease: p21-activated kinase signaling requires C-terminal cleavage of APP at Asp664. J Neurochem 104:1065-1080

Nikolic M, Chou MM, Lu W, Mayer BJ, Tsai LH (1998) The p35/Cdk5 kinase is a neuron-specific Rac effector that inhibits Pak1 activity. Nature 395:194-198 
Nobes CD, Hall A (1995) Rho, rac, and cdc42 GTPases regulate the assembly of multimolecular focal complexes associated with actin stress fibers, lamellipodia, and filopodia. Cell 81:53-62

Nobes CD, Hall A (1999) Rho GTPases control polarity, protrusion, and adhesion during cell movement. J Cell Biol 144:1235-1244

Noll RB, Reiter-Purtill J, Moore BD, Schorry EK, Lovel AM, Vannatta K, Gerhardt CA (2007) Social, emotional, and behavioral functioning of children with NF1. Am J Med Genet A 143a:2261-2273

O'Donnell M, Chance RK, Bashaw GJ (2009) Axon growth and guidance: receptor regulation and signal transduction. Annu Rev Neurosci 32:383-412

O'Donnell WT, Warren ST (2002) A decade of molecular studies of fragile X syndrome. Annu Rev Neurosci 25:315-338

Parrini MC, Camonis J, Matsuda M, de Gunzburg J (2009) Dissecting activation of the PAK1 kinase at protrusions in living cells. J Biol Chem 284:24133-24143

Parrini MC, Lei M, Harrison SC, Mayer BJ (2002) Pak1 kinase homodimers are autoinhibited in trans and dissociated upon activation by Cdc42 and Rac1. Mol Cell 9:73-83

Peca J, Feliciano C, Ting JT, Wang W, Wells MF, Venkatraman TN, Lascola CD, Fu Z, Feng G (2011) Shank3 mutant mice display autistic-like behaviours and striatal dysfunction. Nature 472:437442

Peippo M, Koivisto AM, Särkämö T, Sipponen M, von Koskull H, Ylisaukko-oja T, Rehnström K, Froyen G, Ignatius J, Järvelä I (2007) PAK3 related mental disability: further characterization of the phenotype. Am J Med Genet A 143a:2406-2416

Pensold D, Symmank J, Hahn A, Lingner T, Salinas-Riester G, Downie BR, Ludewig F, Rotzsch A, Haag N, Andreas N et al (2017) The DNA Methyltransferase 1 (DNMT1) Controls the Shape and Dynamics of Migrating POA-Derived Interneurons Fated for the Murine Cerebral Cortex. Cereb Cortex 27:56965714

Penzes P, Beeser A, Chernoff J, Schiller MR, Eipper BA, Mains RE, Huganir RL (2003) Rapid induction of dendritic spine morphogenesis by trans-synaptic ephrinB-EphB receptor activation of the Rho-GEF kalirin. Neuron 37:263-274

Pereanu W, Larsen EC, Das I, Estevez MA, Sarkar AA, SpringPearson S, Kollu R, Basu SN, Banerjee-Basu S (2018) AutDB: a platform to decode the genetic architecture of autism. Nucleic Acids Res 46:D1049-D1054

Pirruccello M, Sondermann H, Pelton JG, Pellicena P, Hoelz A, Chernoff J, Wemmer DE, Kuriyan J (2006) A dimeric kinase assembly underlying autophosphorylation in the p21 activated kinases. J Mol Biol 361:312-326

Pletikos M, Sousa AM, Sedmak G, Meyer KA, Zhu Y, Cheng F, Li M, Kawasawa YI, Sestan N (2014) Temporal specification and bilaterality of human neocortical topographic gene expression. Neuron 81:321-332

Pride NA, Korgaonkar MS, Barton B, Payne JM, Vucic S, North KN (2014) The genetic and neuroanatomical basis of social dysfunction: lessons from neurofibromatosis type 1. Hum Brain Mapp 35:2372-2382

Purcell SM, Moran JL, Fromer M, Ruderfer D, Solovieff N, Roussos P, O'Dushlaine C, Chambert K, Bergen SE, Kahler A et al (2014) A polygenic burden of rare disruptive mutations in schizophrenia. Nature 506:185-190
Pyronneau A, He Q, Hwang JY (2017) Aberrant Rac1-cofilin signaling mediates defects in dendritic spines, synaptic function, and sensory perception in fragile $X$ syndrome. Sci Signal 10 eaan0852

Qu J, Li X, Novitch BG, Zheng Y, Kohn M, Xie JM, Kozinn S, Bronson R, Beg AA, Minden A (2003) PAK4 kinase is essential for embryonic viability and for proper neuronal development. Mol Cell Biol 23:7122-7133

Quintero-Rivera F, Sharifi-Hannauer P, Martinez-Agosto JA (2010) Autistic and psychiatric findings associated with the 3q29 microdeletion syndrome: case report and review. Am J Med Genet A 152a:2459-2467

Radu M, Semenova G, Kosoff R, Chernoff J (2014) PAK signalling during the development and progression of cancer. Nat Rev Cancer 14:13-25

Ramos Cl, Igiesuorobo O, Wang Q, Serpe M (2015) Neto-mediated intracellular interactions shape postsynaptic composition at the Drosophila neuromuscular junction. PLoS Genet 11:e1005191

Rane CK, Minden A (2014) P21 activated kinases: structure, regulation, and functions. Small GTPases. 5:1-11

Rashid T, Banerjee M, Nikolic M (2001) Phosphorylation of Pak1 by the p35/Cdk5 kinase affects neuronal morphology. J Biol Chem 276:49043-49052

Rejeb I, Saillour Y, Castelnau L, Julien C, Bienvenu T, Taga P, Chaabouni H, Chelly J, Ben Jemaa L, Bahi-Buisson N (2008) A novel splice mutation in PAK3 gene underlying mental retardation with neuropsychiatric features. Eur J Hum Genet 16:1358-1363

Richier L, Williton K, Clattenburg L, Colwill K, O'Brien M, Tsang C, Kolar A, Zinck N, Metalnikov P, Trimble WS et al (2010) NOS1AP associates with Scribble and regulates dendritic spine development. J Neurosci 30:4796-4805

Ross CA, Margolis RL, Reading SA, Pletnikov M, Coyle JT (2006) Neurobiology of schizophrenia. Neuron 52:139-153

Rubio MD, Haroutunian V, Meador-Woodruff JH (2012) Abnormalities of the Duo/Ras-related C3 botulinum toxin substrate 1/p21activated kinase 1 pathway drive myosin light chain phosphorylation in frontal cortex in schizophrenia. Biol Psychiatry 71:906914

Sanders LC, Matsumura F, Bokoch GM, de Lanerolle P (1999) Inhibition of myosin light chain kinase by $\mathrm{p} 21$-activated kinase. Science 283:2083-2085

Santini E, Huynh TN, Longo F, Koo SY, Mojica E, Anderson MJ, Bagni C, Klann E (2017) Reducing elF4E-elF4G interactions restores the balance between protein synthesis and actin dynamics in fragile $X$ syndrome model mice. Science Signaling 10:eaan0665

Sells MA, Chernoff J (1997) Emerging from the Pak: the p21activated protein kinase family. Trends Cell Biol 7:162-167

Sivanesan S, Tan A, Rajadas J (2013) Pathogenesis of Abeta oligomers in synaptic failure. Curr Alzheimer Res 10:316-323

Smith KR, Davenport EC, Wei J, Li X, Pathania M, Vaccaro V, Yan Z, Kittler JT (2014) GIT1 and BPIX are essential for GABA (A) receptor synaptic stability and inhibitory neurotransmission. Cell Rep. 9:298-310

Souopgui J, Solter M, Pieler T (2002) XPak3 promotes cell cycle withdrawal during primary neurogenesis in Xenopus laevis. EMBO J 21:6429-6439 
Strochlic TI, Concilio S, Viaud J, Eberwine RA, Wong LE, Minden A, Turk BE, Plomann M, Peterson JR (2012) Identification of neuronal substrates implicates Pak5 in synaptic vesicle trafficking. Proc Natl Acad Sci U S A. 109:4116-4121

Sullivan PF, Kendler KS, Neale MC (2003) Schizophrenia as a complex trait: evidence from a meta-analysis of twin studies. Arch Gen Psychiatry 60:1187-1192

Tabanifar B, Zhao Z, Manser E (2016) PAK5 is auto-activated by a central domain that promotes kinase oligomerization. Biochem J. 473:1777-1789

Tyagi N, Bhardwaj A, Singh AP, McClellan S, Carter JE, Singh S (2014) p-21 activated kinase 4 promotes proliferation and survival of pancreatic cancer cells through AKT- and ERK-dependent activation of NF-KB pathway. Oncotarget. 5:8778-8789

Udo H, Jin I, Kim JH, Li HL, Youn T, Hawkins RD, Kandel ER, Bailey $\mathrm{CH}$ (2005) Serotonin-induced regulation of the actin network for learning-related synaptic growth requires Cdc42, N-WASP, and PAK in Aplysia sensory neurons. Neuron 45:887-901

Walsh KS, Velez JI, Kardel PG, Imas DM, Muenke M, Packer RJ, Castellanos FX, Acosta MT (2013) Symptomatology of autism spectrum disorder in a population with neurofibromatosis type 1. Dev Med Child Neurol 55:131-138

Wang W, Lim L, Baskaran Y, Manser E, Song J (2013) NMR binding and crystal structure reveal that intrinsically-unstructured regulatory domain auto-inhibits PAK4 by a mechanism different from that of PAK1. Biochem Biophys Res Commun 438:169-174

Wang Y, Zeng C, Li J, Zhou Z, Ju X, Xia S, Li Y, Liu A, Teng H, Zhang $K$ et al (2018) PAK2 Haploinsufficiency Results in Synaptic Cytoskeleton Impairment and Autism-Related Behavior. Cell Rep. 24:2029-2041

Willatt L, Cox J, Barber J, Cabanas ED, Collins A, Donnai D, FitzPatrick DR, Maher E, Martin H, Parnau J et al (2005) 3q29 microdeletion syndrome: clinical and molecular characterization of a new syndrome. Am J Hum Genet 77:154-160

Won SY, Park MH, You ST, Choi SW, Kim HK, McLean C, Bae SC, Kim SR, Jin BK, Lee KH et al (2016) Nigral dopaminergic PAK4 prevents neurodegeneration in rat models of Parkinson's disease. Sci Transl Med 8:367ra170

Xia S, Zhou Z, Leung C, Zhu Y, Pan X, Qi J, Morena M, Hill MN, Xie $W$, Jia $Z$ (2016) p21-activated kinase 1 restricts tonic endocannabinoid signaling in the hippocampus. eLife 14:e14653

Yan Z, Kim E, Datta D, Lewis DA, Soderling SH (2016) Synaptic Actin Dysregulation, a Convergent Mechanism of Mental Disorders? J Neurosci 36:11411-11417

Yang N, Higuchi O, Ohashi K, Nagata K, Wada A, Kangawa K, Nishida E, Mizuno K (1998) Cofilin phosphorylation by LIMkinase 1 and its role in Rac-mediated actin reorganization. Nature 393:809-812

Yasui H, Katoh H, Yamaguchi Y, Aoki J, Fujita H, Mori K, Negishi M (2001) Differential responses to nerve growth factor and epidermal growth factor in neurite outgrowth of PC12 cells are determined by Rac1 activation systems. J Biol Chem 276:15298-15305

Zeisel A, Hochgerner $H$, Lönnerberg P, Johnsson A, Memic F, van der Zwan J, Häring M, Braun E, Borm LE, La Manno G et al (2018) Molecular Architecture of the Mouse Nervous System. Cell 174:999-1014.e1022

Zhao L, Ma QL, Calon F, Harris-White ME, Yang F, Lim GP, Morihara T, Ubeda OJ, Ambegaokar S, Hansen JE et al (2006) Role of p21-activated kinase pathway defects in the cognitive deficits of Alzheimer disease. Nat Neurosci 9:234-242

Zhong JL, Banerjee MD, Nikolic M (2003) Pak1 and its T212 phosphorylated form accumulate in neurones and epithelial cells of the developing rodent. Dev Dyn 228:121-127 